This item was submitted to Loughborough's Research Repository by the author.

Items in Figshare are protected by copyright, with all rights reserved, unless otherwise indicated.

\title{
Concurrent La and A-site vacancy doping modulates the thermoelectric response of SrTiO3: experimental and computational evidence
}

\section{PLEASE CITE THE PUBLISHED VERSION}

https://doi.org/10.1021/acsami.7b14231

\section{PUBLISHER}

(C) American Chemical Society

\section{VERSION}

AM (Accepted Manuscript)

\section{PUBLISHER STATEMENT}

This work is made available according to the conditions of the Creative Commons Attribution-NonCommercialNoDerivatives 4.0 International (CC BY-NC-ND 4.0) licence. Full details of this licence are available at: https://creativecommons.org/licenses/by-nc-nd/4.0/

\section{LICENCE}

CC BY-NC-ND 4.0

\section{REPOSITORY RECORD}

Azough, Feridoon, Samuel S. Jackson, Dursun Ekren, Robert Freer, Marco Molinari, Stephen R. Yeandel, Pooja M. Panchmatia, et al.. 2019. "Concurrent La and A-site Vacancy Doping Modulates the Thermoelectric Response of Srtio3: Experimental and Computational Evidence”. figshare. https://hdl.handle.net/2134/27914. 


\title{
Concurrent La and A-site Vacancy Doping Modulates the Thermoelectric Response of $\mathrm{SrTiO}_{3}$. Experimental and Computational Evidence
}

\author{
Feridoon Azough $^{1}$, Samuel S. Jackson ${ }^{1}$, Dursun Ekren ${ }^{1}$, Robert Freer ${ }^{{ }^{*}}$ \\ Marco Molinari $^{2,3}$, Stephen R. Yeandel ${ }^{2,4}$, Pooja M. Panchmatia ${ }^{4}$, Stephen C. Parker ${ }^{2 *}$ \\ David Hernandez Maldonado ${ }^{5}$, Demie M. Kepaptsoglou ${ }^{5}$, Quentin M. Ramasse ${ }^{5}$
}

${ }^{1}$ School of Materials, University of Manchester, Manchester M13 9PL, UK

${ }^{2}$ Department of Chemistry, University of Bath, Claverton Down, Bath, BA2 7AY, UK

${ }^{3}$ Department of Chemistry, University of Huddersfield, Queensgate, Huddersfield, HD1 3DH, UK

${ }^{4}$ Department of Chemistry, Loughborough University, Epinal Way, Loughborough, LE11 3TU, UK

${ }^{5}$ SuperSTEM Laboratory, SciTech Daresbury Campus, Keckwick Lane, Warrington, WA4 4AD, UK

Keywords. Strontium titanate, thermal conductivity, vacancy-cation ordering, perovskite, molecular dynamics, nanostructuring

\begin{abstract}
To help understand the factors controlling the performance of one of the most promising n-type oxide thermoelectrics $\mathrm{SrTiO}_{3}$, we need to explore structural control at the atom level. In $\mathrm{Sr}_{1-\mathrm{x}} \mathrm{La}_{2 \times / 3} \mathrm{TiO}_{3}$ ceramics $(0.0 \leq \mathrm{x} \leq$ 0.9 ), we determined that the thermal conductivity can be reduced and controlled through an interplay of La substitution and A-site vacancies and the formation of a layered structure. The decrease in thermal conductivity with La and A-site vacancy substitution dominates the trend in the overall thermoelectric response. The maximum dimensionless Figure of merit is 0.27 at $1070 \mathrm{~K}$ for composition $\mathrm{x}=0.50$ where half of the A-sites are occupied with La and vacancies. Atomic resolution Z-contrast imaging and atomic scale chemical analysis show that as La content increases, A-site vacancies initially distribute randomly $(\mathrm{x}<0.3)$, then cluster $(\mathrm{x} \sim 0.5)$, and finally form layers $(\mathrm{x}=0.9)$. The layering is accompanied by a structural phase transformation from cubic to orthorhombic, and the formation of $90^{\circ}$ rotational twins and anti-phase boundaries leading to the formation of localized supercells. The distribution of La and A site vacancies contributes to a non-uniform distribution of atomic scale features. This combination induces temperature stable behaviour in the material and reduces thermal conductivity, an important route to enhancement of the thermoelectric performance. A computational study confirmed that the thermal conductivity of $\mathrm{SrTiO}_{3}$ is lowered by the introduction of La and A site vacancies as shown by the experiments. The modelling supports that a critical mass of A site vacancies is needed to reduce thermal conductivity, and that the arrangement of La, Sr and A site vacancies has a significant impact on thermal conductivity only at high La concentration.
\end{abstract}

\section{INTRODUCTION}

Thermoelectric (TE) energy conversion is widely recognized as a promising technology for both electric power generation through waste heat recovery and cooling of electronic devices. ${ }^{1}$ To achieve impact, TE technology must be affordable and effective; this depends critically on the TE performance of the materials. Metal oxide materials are attractive candidates ${ }^{2-4}$ compared to conventional
TE materials because of their affordable large scale production, elemental abundance, low toxicity, and stability in oxidising conditions and at high temperatures. ${ }^{5}$ The effectiveness of a material to convert waste heat into electricity is given by the dimensionless figure of merit (ZT), which is maximized by increasing electrical conductivity and reducing thermal conductivity. ${ }^{2}$ In general it is argued that the material must have a peak ZT greater 
than 1, or at least more than 0.5 over a wide temperature range to be commercially valuable.

Whereas p-type oxide materials (e.g. $\mathrm{Na}_{\mathrm{x}} \mathrm{CoO}_{2}$, $\left.\mathrm{Ca}_{3} \mathrm{Co}_{4} \mathrm{O}_{9}, \mathrm{Bi}_{2} \mathrm{Sr}_{2} \mathrm{Co}_{2} \mathrm{O}_{\mathrm{y}}\right)^{6-9}$ were the first to show competitive thermoelectric properties, the development of an outstanding n-type material has proved more challenging. Most of the proposed ntype materials, including $\mathrm{CaMnO}_{3},{ }^{10-12} \mathrm{SrTiO}_{3},{ }^{2,}, 13-20$ and $\mathrm{Ba}_{6-3 x} \mathrm{Nd}_{8+2 \mathrm{x}} \mathrm{Ti}_{18} \mathrm{O}_{54},{ }^{21,22}$ are based on the perovskite and tungsten bronze structures. Of these perovskite structured materials have been at the center of recent development of n-type high temperature thermoelectric ceramics, particularly materials based on $\mathrm{SrTiO}_{3}$. Both experimental and computational methodologies aid the design and engineering of desirable thermoelectric structures with enhanced material properties. Successful applications have been related to both nanostructuring ${ }^{2,20}$ and band engineering. ${ }^{3,11,21}$ However, the major advantage of the $\mathrm{ABO}_{3}$ perovskite structure is its ability to accommodate dopants on both the B-site and on the A-site. One of the most promising substitutions is with a trivalent cation, $\mathrm{A}^{3+}$, into $\mathrm{A}^{2+} \mathrm{BO}_{3}$, which can be accommodated by the introduction of vacancies in the A sub-lattice, such as in the solid solution $\mathrm{SrTiO}_{3}-\mathrm{La}_{2 / 3} \mathrm{TiO}_{3}$ (i.e. $\left.\mathrm{Sr}_{1-\mathrm{x}} \mathrm{La}_{2 \mathrm{x} / 3} \mathrm{TiO}_{3}\right)^{15}, 16,23$ This has led to very encouraging TE properties, which are sensitive to the structures of the materials. ${ }^{2,16}$

At room temperature, $\mathrm{SrTiO}_{3}$ has a perovskite, aristotype, cubic structure, with lattice parameter of $\mathrm{a}=3.905 \AA$ and space group $P m \overline{3} m .^{24}$ The structure remains cubic up to the melting point. The $\mathrm{La}_{2 / 3} \mathrm{TiO}_{3}$ end member can be stabilized by small additions, less than $10 \%$, of a perovskite compound such as $\mathrm{LaAlO}_{3}, \mathrm{CaTiO}_{3}$ or $\mathrm{SrTiO}_{3}{ }^{25-27}$ The structure of this end member is characterized by layered ordering of La cations onto the perovskite A-sites, such that one layer of the A-sites is essentially fully occupied by La cations and the next layer is shared between La and A-site vacancies. ${ }^{28,} 29$ This cation-vacancy ordering reduces the symmetry to tetragonal, and leads to the doubling of the c-parameter (relative to that in the parent perovskite). The space group is $P 4 / \mathrm{mmm}$. The tetragonal symmetry is stable to about $400^{\circ} \mathrm{C}$. The room temperature structure shows an orthorhombic distortion with lattice parameters doubled in all three directions with $\mathrm{Cmmm}$ as space group. ${ }^{29}$ Using X-ray diffraction and high-resolution transmission electron microscopy (HRTEM) Battle et al. directly observed $\mathrm{Sr} / \mathrm{La}$ sub-lattice features in perovskite structure $\mathrm{Sr}_{1-3 \mathrm{y} / 2} \mathrm{La}_{\mathrm{y}} \mathrm{TiO}_{3}(0.25 \leq \mathrm{y} \leq 0.6) .{ }^{30}$

This A site doping strategy with $\mathrm{SrTiO}_{3}$ has the advantage of lowering the high thermal conductivity (approximately $11.0-3.2 \mathrm{~W} / \mathrm{m} . \mathrm{K}$ in the temperature range of $300 \sim 1000 \mathrm{~K})^{15}$ via a structural change of the parent material, which depending on the $\mathrm{La}^{3+}$ content may form a layered structure. Reduction of lattice thermal conductivity is essential to improve the thermoelectric response of $\mathrm{SrTiO}_{3}$ based materials.

We have already demonstrated that there is an ordered distribution of A-site vacancies in $\mathrm{La}_{2 / 3} \mathrm{TiO}_{3}$ stabilized with $\mathrm{LaAlO}_{3}$ perovskite. ${ }^{31}$ In the present study, we employed experimental and computational techniques, including atomic level imaging and chemical characterization using scanning transmission electron microscopy (STEM), highangle annular dark field (HAADF) and electron energy loss spectroscopy (EELS), along with molecular dynamics calculations to explain the role of the doping (A-site vacancy - cation distribution), the layering formation with increased La content, and the role of sub-grain features associated with the crystal structure in the $\mathrm{SrTiO}_{3}-\mathrm{La}_{2 / 3} \mathrm{TiO}_{3}$ system. This provides a route to determine the complex structure - thermal conductivity property relationships and a means to improve the material's thermoelectric properties through design and engineering. The prime objective of this study is thus to understand thermal transport in perovskite structured oxides, and specifically factors other than oxygen vacancies. For this reason the focus is the behavior of samples prepared under oxidizing conditions so that the additional complexities of oxygen vacancies are eliminated. Thermal and electrical data are presented for samples prepared under both oxidizing and reducing conditions to set the results in context.

\section{METHODS}

Experimental Methodology. Polycrystalline samples of $\mathrm{Sr}_{1-\mathrm{x}} \mathrm{La}_{2 \times / 3} \mathrm{TiO}_{3}(\mathrm{x}=0.0,0.1,0.3,0.5,0.7$ and 0.9 , hereafter denoted as $\mathrm{x} 0$, x10 etc.) were produced by standard solid-state reaction techniques. All powders were $99.9 \%$ purity and obtained from Sigma Aldrich. The $\mathrm{La}_{2} \mathrm{O}_{3}$ was first dried at $1173 \mathrm{~K}$ for $6 \mathrm{~h}$ prior to mixing with $\mathrm{TiO}_{2}$ and $\mathrm{SrCO}_{3}$ in the required stoichiometric ratios. The powders were mixed in a vibratory mill for 18 hours with $8 \mathrm{~mm} \mathrm{Zr}$ balls and propan-2-ol in a 1:1:1 ratio. After drying the powders were calcined for $4 \mathrm{~h}$ at $1373 \mathrm{~K}$, then re-milled under the conditions described above and dried before pressing in a $20 \mathrm{~mm}$ die in a uniaxial press at $25 \mathrm{MPa}$.

The compacts were sintered at $1733 \mathrm{~K}$ for $4 \mathrm{~h}$ in air, and then cooled at the slow rate of $60^{\circ} \mathrm{C} / \mathrm{h}$ to avoid oxygen loss. One set of samples was sintered under reducing atmosphere $\left(\mathrm{Ar}-5 \% \mathrm{H}_{2}\right)$ at $1733 \mathrm{~K}$ for 4 hours. The thermoelectric response of all samples was evaluated. Samples labelled with the letter "A" were air sintered, whilst those labelled " $\mathrm{H}$ " were sintered under reducing conditions. 
Samples for X-ray diffraction were cut and then ground using $4000 \mathrm{SiC}$ paper. X-ray diffraction was performed with a Philips X'Pert Pro diffractometer with $0.0084^{\circ}$ step size ( $4 \mathrm{~s}$ per step) between $5^{\circ}$ and $80^{\circ}$. Rietveld analysis of the data was undertaken using TOPAS 4.2 software (Bruker AXS, Karlsruhe, Germany). ${ }^{32}$

The microstructure of the polished surface of the samples was analysed using a Philips ${ }^{\circledR}$ XL30 field emission gun (FEG)-SEM HKL ${ }^{\circledR}$ equipped with an energy-dispersive X-ray (EDX) detector.

Samples for TEM and STEM investigation were prepared by both standard crushing and ion beam thinning techniques. For ion beam-thinning, specimens were first ground on 1200 grade $\mathrm{SiC}$ to reduce the thickness to $\sim 300 \mu \mathrm{m}$. They were ultrasonically cut into $3 \mathrm{~mm}$ diameter disks (Model KT150; Kerry Ultrasonic Ltd.) then dimpled (Model D500; VCR Group, San Francisco, CA) to reduce the thickness of the centre of the disk to $30 \mu \mathrm{m}$. Finally, the disks were ion beam thinned (using a Gatan precision ion polishing system model 691; PIPS $^{\mathrm{TM}}$ ) operating at 4-6 kV. For the crushing method, the sintered disks were crushed to powder using an agate mortar and pestle. Grains of individual powders were dispersed in chloroform, dropped onto a copper grid covered with a holey carbon film, and then dried. Structures were initially investigated using selected area electron diffraction (SAED) and high-resolution transmission electron microscopy (HRTEM) techniques using a FEI FEGTEM (Tecnai G2, Hillsboro, OR) operating at $300 \mathrm{kV}$. Subsequently, atomic level resolution level structural characterization was carried out using an aberration-corrected Nion microscope (UltraSTEM100; Nion Company, Kirkland, WA) located at the Daresbury SuperSTEM Laboratory in the United Kingdom.

Thermal conductivity was obtained from measurement of the density (Archimedes method), thermal diffusivity (laser flash, built in-house) and heat capacity (Netzsch STA 449 C); the latter two measured in an $\mathrm{Ar}$ atmosphere. For thermal diffusivity measurements the pellets were $10 \mathrm{~mm}$ in diameter, $1 \mathrm{~mm}$ thick, polished to a $1 \mu \mathrm{m}$ finish and coated in graphite. For heat capacity measurements the pellets were $4 \mathrm{~mm}$ in diameter and the surface polished to a $1 \mu \mathrm{m}$ finish.

An ULVAC $^{\circledR}$ ZEM- ${ }^{\circledR}$ was used to determine the electrical conductivity and Seebeck coefficients of all the samples from temperature to $1100 \mathrm{~K}$.

Computational Methodology. The thermal conductivity was calculated using the Green-Kubo method $^{33,34}$ as implemented in the classical molecular dynamics code LAMMPS ${ }^{35}$ (Large-scale Atomic/Molecular Massively Parallel Simulator).
All calculations were performed using the partialcharge rigid-ion potential model developed by Teter $^{36}$ as detailed in Table 1 . All structures were simulated in the temperature range of 500-1100 K. At each temperature, each structure was equilibrated for $50 \mathrm{ps}$ with a time step of $1 \mathrm{fs}$ using an NPT triclinic ensemble with a Nose-Hoover thermostat and barostat. The lattice vectors were averaged every $10 \mathrm{fs}$ and the averaged vectors were then imposed on the final structure for the heat-flux data collection. The average total energy was collected over a time of $5 \mathrm{~ns}$. Heat-flux data was collected for $20 \mathrm{~ns}$ sampling every $10 \mathrm{fs}$. The heat-flux was numerically autocorrelated and integrated to give thermal conductivity as a function of decay time, which was then averaged over a portion of the integral to reduce the noise in the thermal conductivity. ${ }^{37}$

Table 1. The potential model developed by Teter ${ }^{36}$ with the interactions based on Buckingham potential forms between cations and anions. Partial charges are superscripted.

\begin{tabular}{|c|c|c|c|}
\hline Interaction & $\mathbf{A}(\mathbf{e V})$ & $\mathbf{p ~ ( \mathbf { A } )}$ & $\mathbf{C}\left(\mathbf{e V \times} \AA^{6}\right)$ \\
\hline $\mathrm{O}^{-1.2}-\mathrm{O}^{-1.2}$ & 1844.75 & 0.3436 & 192.58 \\
\hline $\mathrm{Sr}^{-1.2}-\mathrm{O}^{-1.2}$ & 14566.64 & 0.2450 & 81.77 \\
\hline $\mathrm{La}^{1.8}-\mathrm{O}^{-1.2}$ & 4369.39 & 0.2786 & 60.28 \\
\hline $\mathrm{Ti}^{2.4}-\mathrm{O}^{-1.2}$ & 23707.91 & 0.1856 & 14.51 \\
\hline
\end{tabular}

To calculate the formation energies of the $\mathrm{Sr}_{1}$ ${ }_{x} \mathrm{La}_{2 \times / 3} \mathrm{TiO}_{3}$ phases the total energies of the binary oxides were calculated at $500 \mathrm{~K}$ using molecular dynamics using a $1.0 \mathrm{fs}$ timestep and Nose-Hoover thermostats and barostats (using established crystal structures $^{38-40}$ ). Each system was equilibrated under an anisotropic NPT ensemble for $0.5 \mathrm{~ns}$, followed by a $0.5 \mathrm{~ns}$ NVT ensemble to ensure the systems had reached equilibrium. This equilibration was then followed by a 5 ns NVT ensemble to collect the average total energy of the systems. The configurations for $\mathrm{SrO}$ was a $5 \times 5 \times 5$ expansion of a unit cell $\mathrm{a}=\mathrm{b}=\mathrm{c}=5.1615 \AA, \alpha=\beta=\gamma=90^{\circ}$, for rutile $\mathrm{TiO}_{2}$ was a $5 \times 5 \times 7$ expansion of a unit cell $\mathrm{a}=\mathrm{b}=$ $4.5941 \AA$, $c=2.9589 \AA, \alpha=\beta=\gamma=90^{\circ}$, and for $\mathrm{La}_{2} \mathrm{O}_{3}$ was a 6 × 4 x 4 expansion of a unit cell $\mathrm{a}=3.9381 \AA$, $b=6.8139 \AA, c=6.1361 \AA, \alpha=\beta=\gamma=90^{\circ}$ (this cell is double the size of the hexagonal unit cell and orientated to be orthorhombic).

All structural models were designed using the METADISE code. ${ }^{41}$ Three materials were selected for in-depth modeling, corresponding to experimental compositions of $\mathrm{x} 20$, x 50 , and $\mathrm{x} 90$. Composition $\mathrm{x} 20$ has low A-site vacancy and lanthanum concentrations, $x 50$ is the mid-point in the range, and $\times 90$ has high A-site vacancy and lanthanum concentrations. The models were 
generated to reflect the structural features of experimental samples inferred from X-ray and STEM-HAADF-EELS data, which include a layered structure as the $\mathrm{La}$ and A-site vacancy concentrations increase. As well as having three different compositions, each composition was modelled for three different structural configurations, which enabled us to compare and ultimately predict designs for functional materials with enhanced properties.

Table 2. Composition of $\mathrm{Sr}_{1-x} \mathrm{La}_{2 \times 3} \mathrm{TiO}_{3}$ models for $\mathrm{x}=20,50$ and 90 in computational model structures xNRand, $x N L a S r$ and $x N L a V$. Square brackets in $x N L a S r$ and $x N L a V$ models denote the two groups of layers, whether fully or partially occupied. VA denotes an A site vacancy.

\begin{tabular}{|c|c|c|c|}
\hline & $\mathbf{x 2 0}$ & $\mathbf{x 5 0}$ & $\mathbf{x 9 0}$ \\
\hline$x N R a n d$ & $\mathrm{La}_{0.13} \mathrm{Sr}_{0.8} \mathrm{VA}_{0.07} \mathrm{TiO}_{3}$ & $\mathrm{La}_{0.33} \mathrm{Sr}_{0.5} \mathrm{VA}_{0.17} \mathrm{TiO}_{3}$ & $\mathrm{La}_{0.6} \mathrm{Sr}_{0.1} \mathrm{VA}_{0.30} \mathrm{TiO}_{3}$ \\
\hline$x N \mathrm{NaSr}$ & {$\left[\mathrm{La}_{0.13} \mathrm{Sr}_{0.37}\right]\left[\mathrm{Sr}_{0.43} \mathrm{VA}_{0.07}\right] \mathrm{TiO}_{3}$} & {$\left[\mathrm{La}_{0.33} \mathrm{Sr}_{0.17}\right]\left[\mathrm{Sr}_{0.33} \mathrm{VA}_{0.17}\right] \mathrm{TiO}_{3}$} & {$[\mathrm{La0} .5]\left[\mathrm{La}_{0.1} \mathrm{Sr}_{0.1} \mathrm{VA}_{0.3}\right] \mathrm{TiO}_{3}$} \\
\hline $\mathrm{xNLaV}$ & {$\left[\mathrm{Sr}_{0.55}\right]\left[\mathrm{La}_{0.13} \mathrm{Sr}_{0.3} \mathrm{VA}_{0.07}\right] \mathrm{TiO}_{3}$} & {$\left[\mathrm{Sr}_{0.5}\right]\left[\mathrm{La}_{0.33} \mathrm{VA}_{0.17}\right] \mathrm{TiO}_{3}$} & {$\left[\mathrm{La}_{0.4} \mathrm{Sr}_{0.1}\right]\left[\mathrm{La}_{0.2} \mathrm{VA}_{0.3}\right] \mathrm{TiO}_{3}$} \\
\hline
\end{tabular}

The three models were constructed from a $12 \times 12$ x 12 expansion of the $\mathrm{ATiO}_{3}$ cubic structure. This structure comprises of 12 alternating parallel layers of A sites; of these 6 are fully occupied (FO) and 6 are partially occupied (PO). This separation is conceptually needed as the experimental $\mathrm{Sr}_{1}$ ${ }_{x} \mathrm{La}_{2 \times / 3} \mathrm{TiO}_{3}$ is a layered structure for high $\mathrm{x}$.

As our starting computational configuration has now two groups of A site layers, one FO and the other PO, we can start populating the groups. We defined two layered model systems. "xNLaSr" maximizes the separation between $\mathrm{La}$ and A site vacancies, whereas "xNLaV" maximizes the interaction between $\mathrm{La}$ and $\mathrm{A}$ site vacancies. For comparison, we have generated a randomly distributed arrangement named model "xNRand", which randomly distributes all $\mathrm{La}, \mathrm{Sr}$ and A site vacancies on all the A sites, regardless of the group.

For the layered structures $x N L a S r$ and $x N L a V$, in both cases they are comprised of alternating fully occupied (FO) and partially occupied (PO) layers. The difference between the structures is in the composition of the two groups of layers. In xNLaSr the FO layers contain all the available $\mathrm{La}$, while the PO layers contain all the available Sr (Table 2). Thus at $\mathrm{x} 90$ there is a clear partitioning, but as the numbers of La are reduced (e.g. x20 and x50) the A sites in the FO layers are replaced by $\mathrm{Sr}$. $\mathrm{xNLaV}$ represents the opposite extreme, whereby the PO layers contain all the available $\mathrm{La}$ and the FO layer contain all the available $\mathrm{Sr}$ (Table 2). Again the precise numbers of each species are governed by the composition. Thus, for example at $\mathrm{x} 20$, when the $\mathrm{La}$ concentration is much reduced, the remaining sites in the PO layers is occupied by $\mathrm{Sr}$.

\section{RESULTS AND DISCUSSION}

Structural Bulk Properties. High density (> 97\% theoretical) crack-free sintered samples were produced for all air sintered $\mathrm{Sr}_{1-\mathrm{x}} \mathrm{La}_{2 \times / 3} \mathrm{TiO}_{3}$ formulations. Samples sintered under reducing conditions were of marginally lower density, but generally $95 \%$ dense and above. The density data (i.e. experimental values and \% theoretical values) for the samples are shown in Table 3. Half the ceramics were sintered in air to reduce the effect of oxygen vacancies and electronic contribution $\left(\mathrm{Ti}^{3+}\right)$ on the thermal properties of the material. This enables us to focus on the contribution due to $\mathrm{La}$ and A-site vacancy doping. The remaining samples were sintered under reducing conditions for comparison purposes.

Phase Analysis. XRD spectra for the $\mathrm{Sr}_{1-}$ ${ }_{x} \mathrm{La}_{2 \times / 3} \mathrm{TiO}_{3}$ materials sintered in air are presented in Figure 1. All the spectra could be refined based on a perovskite structure without the presence of reflections arising from impurity phases. The XRD results indicate that the $\mathrm{La}_{2 / 3} \mathrm{TiO}_{3}$ end member, i.e. sample $\mathrm{x} 90$, can be stabilized by $\mathrm{SrTiO}_{3}$. This was already proven for $\mathrm{LaAlO}_{3}{ }^{42}$ and $\mathrm{CaTiO}_{3}{ }^{26}$ Rietveld refinement for samples $\mathrm{x} 10$ and $\mathrm{x} 90$ showed a cubic $(P m \overline{3} \mathrm{~m})$ structure and an orthorhombic $(\mathrm{Cmmm})$ structure respectively. Sample x30 contains a tetragonal, $I 4 / \mathrm{mcm}$ phase in addition to a cubic phase and samples $\mathrm{x} 50$ and $\mathrm{x} 70$ contain an $14 / \mathrm{mcm}$ phase in addition to an orthorhombic $\mathrm{Cmmm}$ phase. The phase content of the $\mathrm{Sr}_{1-\mathrm{x}} \mathrm{La}_{2 \times / 3} \mathrm{TiO}_{3}$ ceramics sintered in air is presented in Table 3. Data for samples sintered under reducing conditions are not significantly different. The results in Figure 1 and Table 3 support the work of Howard et al. ${ }^{27,} 28$ and $\mathrm{Lu}$ et al ${ }^{43}$ for the $\mathrm{Sr}_{1-\mathrm{x}} \mathrm{La}_{2 \times / 3} \mathrm{TiO}_{3}$ system, and agree with the findings of Kovalevsky et al ${ }^{44}$ for the structural changes at the $\mathrm{SrTiO}_{3}$ rich end of the $\mathrm{SrTiO}_{3}-\mathrm{Pr}_{2 / 3} \mathrm{TiO}_{3}$ system. The refined lattice parameters are summarized in Figure 2. 
Table 3. Density and phase content data for the $\mathrm{Sr}_{1-x} \mathrm{La}_{2 \mathrm{x} / 3} \mathrm{TiO}_{3}$ ceramics.

\begin{tabular}{|c|c|c|c|c|c|}
\hline $\mathrm{Sr}_{1-\mathrm{x}} \mathrm{La}_{2 \mathrm{x} / 3} \mathrm{TiO}_{3}$ & $\begin{array}{l}\text { Expt. Density } \\
\quad\left(\mathrm{g} \mathrm{cm}^{-3}\right)\end{array}$ & $\begin{array}{l}\text { Theoretical } \\
\text { Density (\%) }\end{array}$ & $\begin{array}{c}\text { Cubic } \\
\text { Phase (\%) }\end{array}$ & $\begin{array}{l}\text { Tetragonal } \\
\text { Phase (\%) }\end{array}$ & $\begin{array}{c}\text { Orthorhombic } \\
\text { Phase (\%) }\end{array}$ \\
\hline $\mathrm{xOA}$ & $5.08 \pm 0.092$ & 99.2 & 100 & - & - \\
\hline$x 10 A$ & $5.100 \pm 0.096$ & 99.1 & 100 & - & - \\
\hline $\mathrm{X} 10 \mathrm{H}$ & $5.094 \pm 0.087$ & 98.9 & & & \\
\hline $\mathrm{x} 30 \mathrm{~A}$ & $5.093 \pm 0.048$ & 98.1 & 12 & 88 & - \\
\hline $\mathrm{X} 30 \mathrm{H}$ & $4.915 \pm 0.018$ & 95.3 & & & \\
\hline$x 50 A$ & $5.126 \pm 0.024$ & 97.9 & - & 77 & 23 \\
\hline $\mathrm{X} 50 \mathrm{H}$ & $5.124 \pm 0.024$ & 97.3 & & & \\
\hline$x 70 A$ & $5.132 \pm 0.095$ & 97.2 & - & 7 & 93 \\
\hline $\mathrm{X70H}$ & $5.023 \pm 0.016$ & 94.9 & & & \\
\hline x90A & $5.252 \pm 0.046$ & 98.4 & - & - & 100 \\
\hline $\mathrm{X} 90 \mathrm{H}$ & $4.972 \pm 0.019$ & 92.0 & & & \\
\hline
\end{tabular}

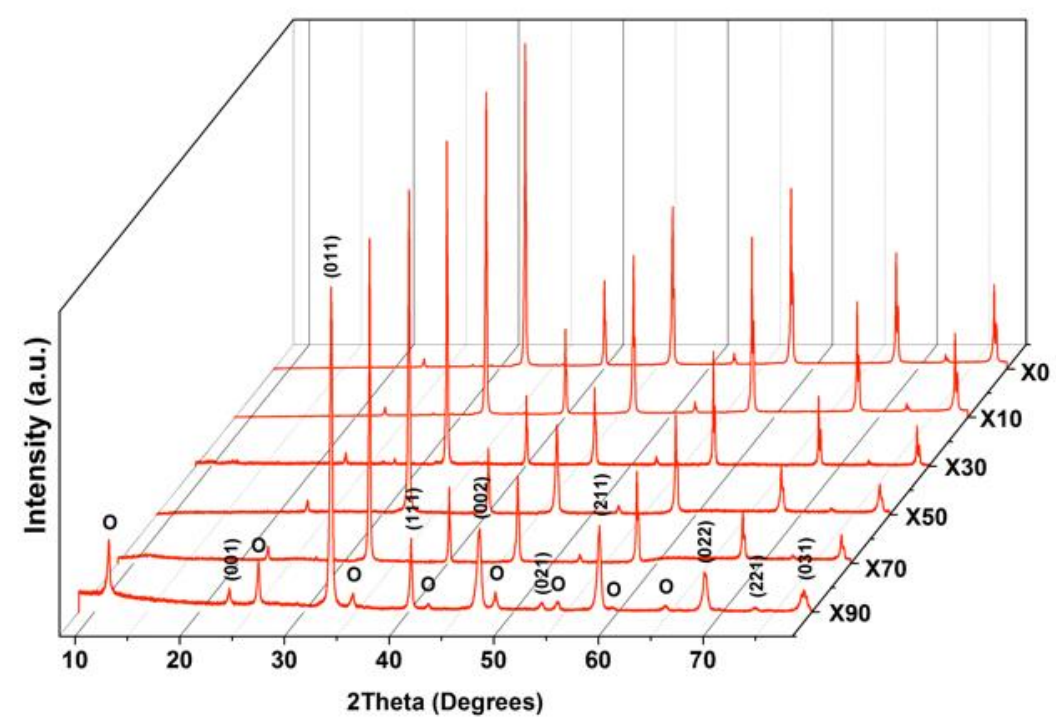

Figure 1. XRD Spectra for $\mathrm{Sr}_{1-x} \mathrm{La}_{2 \times / 3} \mathrm{TiO}_{3}$ ceramics sintered in air. The intensities have been normalised to the (110) main peak of perovskite phase. The peaks from orthorhombic phase are labelled by circles. The first peak in the XRD spectrum for $x 90$ (at $2 \theta \approx 11.36^{\circ}$ ) is due to cation/vacancy ordering along the c-direction. From $x 10$ to $\times 90$ the weighted profile $\mathrm{R}$ factor values decrease from 15.0 to 7.4 ; the Goodness of fit values vary from 1.27 to 1.56 . 


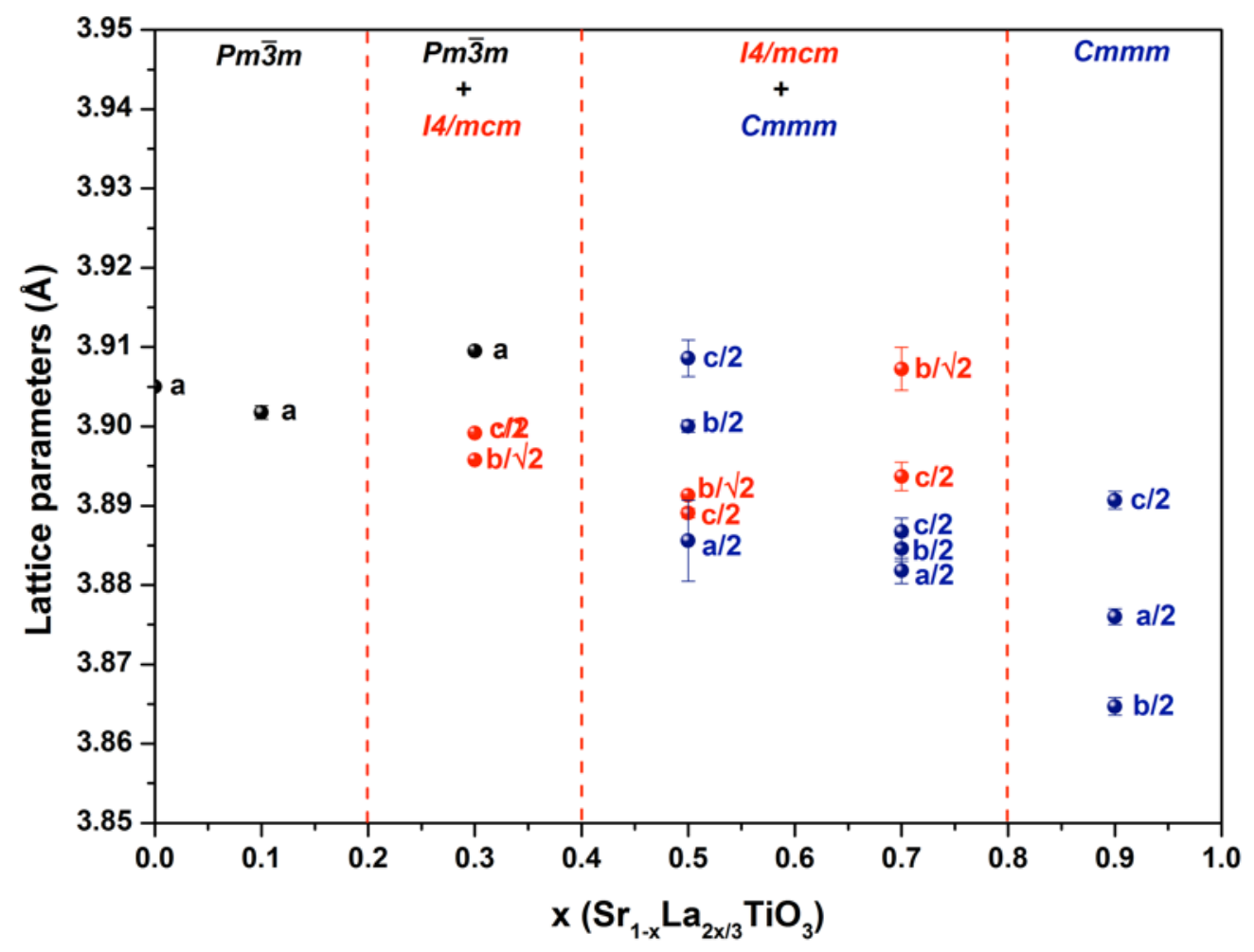

Figure 2. Refined lattice parameters for $\mathrm{Sr}_{1-x} \mathrm{La}_{2 \times / 3} \mathrm{TiO}_{3}$ ceramics sintered in air as a function of La content.

\section{Electron Microscopy.}

Figure 3 shows a typical SEM micrograph of the microstructure of $\mathrm{Sr}_{1-x} \mathrm{La}_{2 \times / 3} \mathrm{TiO}_{3}$ ceramics; this image is for $\mathrm{x} 10 \mathrm{~A}$. For all compositions, the grains are equiaxed in shape with narrow grain size distributions. Most individual grains are in the 5-10 $\mu \mathrm{m}$ range.

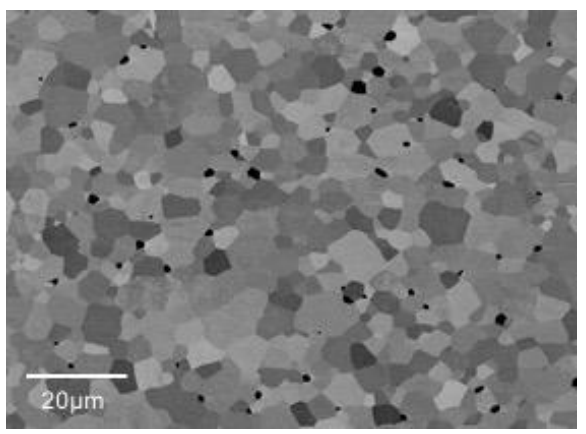

Figure 3 SEM micrograph of air sintered sample $\times 10 \mathrm{~A}$

To define the effect of A-site vacancies on the thermal conductivity of $\mathrm{SrTiO}_{3}$, detailed TEMSADP (Selected Area Diffraction Pattern) for the major zone axes and atomically resolved STEMHAADF-EELS characterization of the air sintered ceramic $\mathrm{x} 90 \mathrm{~A}$ (having the highest vacancy content) were performed. Above 10 mole $\%, \mathrm{SrTiO}_{3}$ stabilizes the $\mathrm{La}_{2 / 3} \mathrm{TiO}_{3}$ end member and gives a single phase ceramic, with an orthorhombic $\mathrm{Cmmm}$ unit cell where lattice parameters $(a=7.74 \AA, b=7.7204 \AA$ and $c=7.782 \AA$ ) are doubled compared to those of the $\mathrm{SrTiO}_{3}$ cubic cell. The cell doubling results from cation/vacancy ordering and out of phase octahedral tilting. ${ }^{45}$ SADPs for two main zone axes [001] and [100] for $x 90$ are shown in Figure 4(a,b), and confirm the orthorhombic symmetry with $\mathrm{Cmmm}$ as space group with $\mathrm{a} \approx \mathrm{b} \approx \mathrm{c} \approx 2 \mathrm{a}_{\text {perovskite, }}$, where $a_{\text {perovskite }}$ is the size of the cubic $\operatorname{Pm} \overline{3} m$ parent unit cell. Diffraction patterns for samples sintered under reducing conditions are very similar.

The [100] schematic projection of orthorhombic Cmmm structure for $\mathrm{x} 90$ deduced from XRD analysis is presented in Figure $4 \mathrm{c}$. The core of the structure is the tilted Ti-oxygen octahedra. The $4 g$ A1-sites are fully occupied by La and the $4 h$ A2sites partially occupied by La $(40 \%)$; together they are arranged in a layered manner, with the unit cell indicated on Figure 4c. 

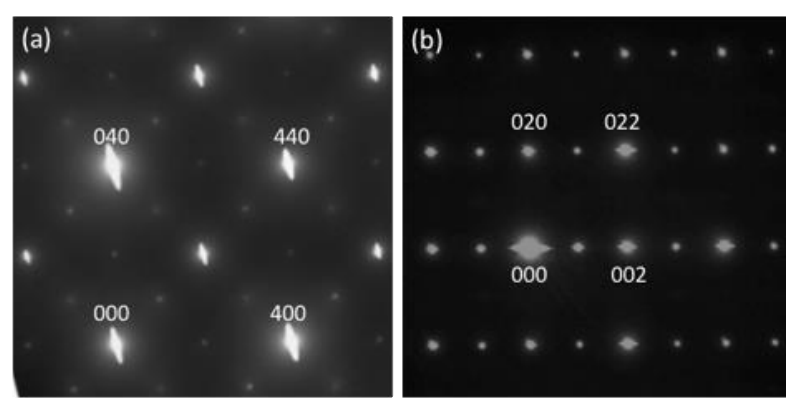

(c)

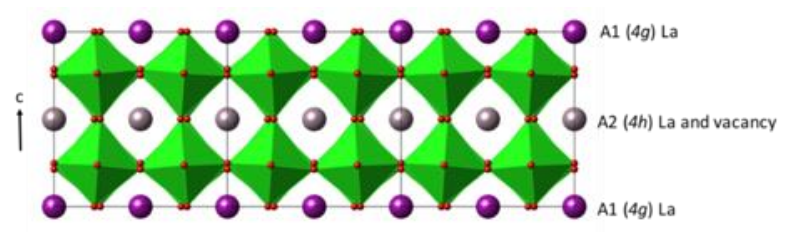

Figure 4. SADPs for ceramic x90A: (a) [001] and (b) [100] zone axes, and (c) schematic representation of the crystal structure of $\mathrm{x} 90 \mathrm{~A}$ along the a-axis.

As the X-ray data are volume-averaged (the typical minimum value for crystallite size used in the structural refinement is $\sim 50 \mathrm{~nm}$ ), atomic resolution characterization was performed to observe atomic scale features. The HAADF-EELS data for ceramic x90 (Figure 5) provides direct evidence of the layered distribution of La cations suggested in the schematic projection (Figure 4c). Figure $5 \mathrm{a}$ is a HAADF image, obtained by rigid registration of a series (typically 20) of images of the same area acquired in rapid succession - thus providing higher signal-to-noise and precision. Such images will hereafter be denoted 'stacked images' for simplicity. The image shows alternating rows of atomic columns with differing intensities (i.e. A1, La1 and A2, La2 sites of the structure). However, intensity profiles for the two rows with different intensities (Figure 5a) show small variations for the intensity for A1 rows (Figure 5b) with much larger differences for the intensity of rows of A2 atomic columns (Figure 5c), suggesting that the distribution of $\mathrm{La}$ and vacancies is not uniform. There are therefore atomic columns with high La concentration and atomic columns with high vacancy content (arrowed in Figure 5c). Figure 5 (d,e,f) presents EELS maps for La, obtained by integrating the EELS signal acquired at each point over a suitable energy window above the $\mathrm{La}^{-\mathrm{M}_{4,5}}$ ionisation edge, after subtraction of the decaying background intensity using a power law model. These maps confirm that the variation of intensity in HAADF images specifically for the A2-sites corresponds to a relative variation in La content of the atomic columns. This variation in the $\mathrm{La}$ and vacancy content in A2-sites is known to cause further non-uniform displacement of B-site cations (Ti) and Ti-O octahedral distortions which already exist in A-site deficient perovskites, ${ }^{46}$ manifesting itself as non-uniformity and disorder in the structure. This is thought to contribute to additional phonon scattering specifically at low temperatures thus creating temperature-stable, glass-like thermal conductivity behavior. It should be noted that HAADF images for ceramic $\mathrm{x} 90$ are reminiscent of HAADF images of $\mathrm{LaAlO}_{3}$ stabilized $\mathrm{La}_{2 / 3} \mathrm{TiO}_{3}$, that we reported for the first time, showing the vacancies in a A-site deficient perovskite using HAADF imaging. ${ }^{26,31}$ It also resembles the Z-contrast images of recently published data for $\mathrm{CaTiO}_{3}$ stabilized $\mathrm{La}_{2 / 3} \mathrm{TiO}_{3} .{ }^{47}$ perovskite using HAADF imaging. ${ }^{26,31}$

Following the confirmation of the crystal structure of ceramic $\mathrm{x} 90$, further analysis was performed to investigate the sub-grain features of the material. Figure 6 presents [100] zone axis TEM data for $\mathrm{x} 90$. The material is characterized by a high density of twins (Figure 6a). On the basis of (currently unpublished) work on the related $(\mathrm{Sr}, \mathrm{Pr}) \mathrm{TiO}_{3}$ system we expect the phase transformation induced twin boundaries to be present in all the compositions of this study except for cubic x10. Full analysis to confirm this prediction would require a substantial separate investigation. HRTEM data for $\mathrm{x} 90$ for one of the twin boundaries and the corresponding Fourier Transform (FFT) for the two domains and their boundary are shown in Figure 6b. The FFT for both domains can be indexed as corresponding to the [100] zone axis of orthorhombic Cmmm (as shown in Figure 6b), which are rotated $90^{\circ}$ to each other to form the twin boundary. This symmetry-breaking, phase-transition-induced type of twin boundary has been frequently observed in orthorhombic perovskites $^{48}$ and may contribute, by additional phonon scattering, to reducing thermal conductivity. In our recent experimental and computational study of the $\mathrm{CaMnO}_{3}$ based thermoelectric, ${ }^{12,49}$ this proposal has been verified. In addition to $90^{\circ}$ rotational twin boundaries, antiphase type domain boundaries were observed in the microstructure of x90; an example is shown in Figure 6c. It is characterized by movement of the two domains with a displacement vector of $1 / 2$ of the length of the $c$ axis. This type of boundary has been observed in the microstructure of orthorhombic perovskites $\left(\mathrm{CaTiO}_{3}\right.$ based compositions) and attributed to antiparallel Asite cation movement or, out of phase rotation of oxygen octahedra. ${ }^{48-50}$ The presence of antiphase boundaries may also have positive effects on the reduction of thermal conductivity by providing additional phonon scattering sites. 

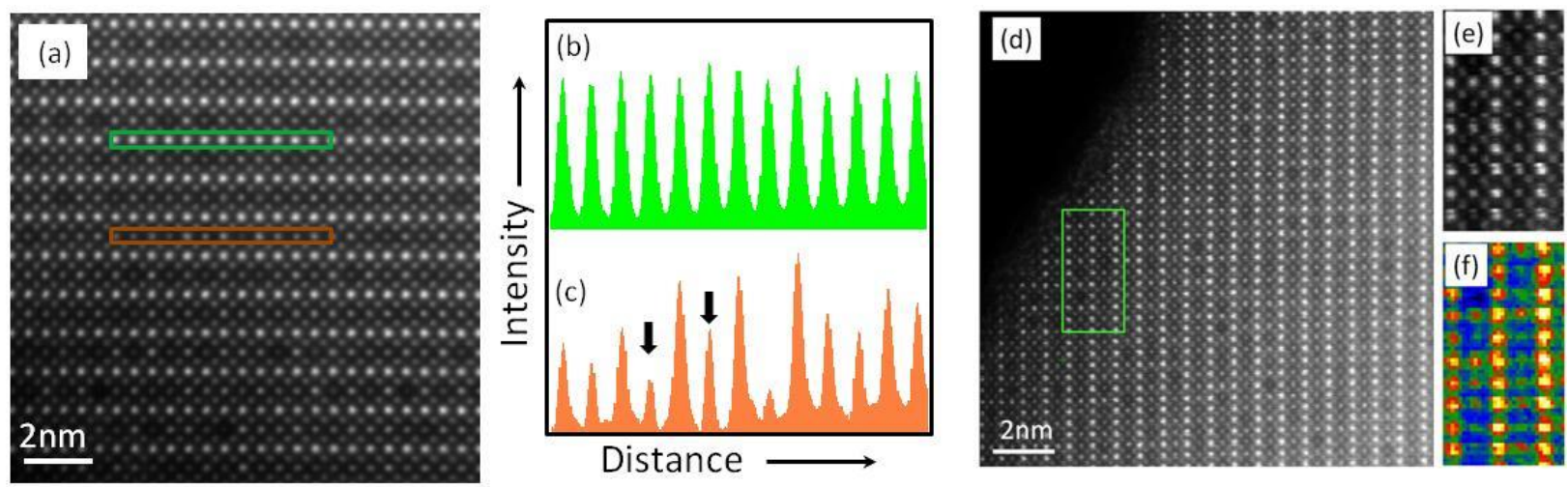

Figure 5. [100] zone axis HAADF-EELS data for $x 90 A$ sample: (a) stacked HAADF image, and intensity profiles for A1 (b) and A2 site (c); (d), HAADF image, (e) HAADF survey and (f) La EELS M4,5 map.
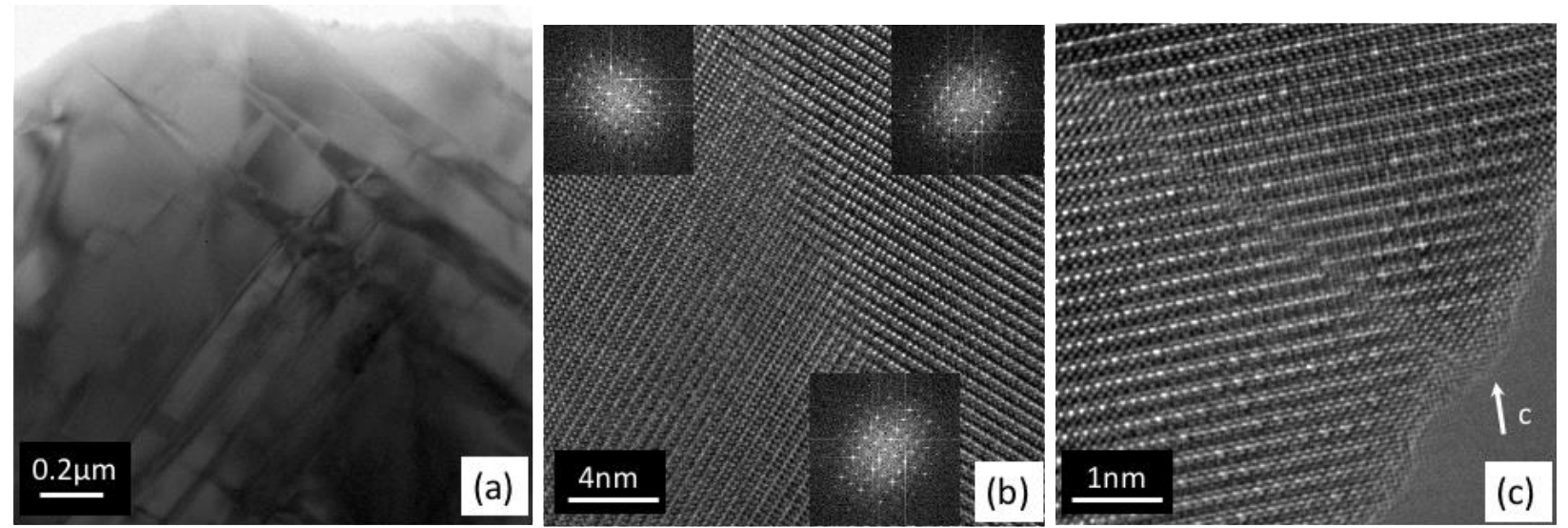

Figure 6. TEM data for sub-grain features in ceramic x90A: (a) TEM image showing twinned microstructure; (b) HRTEM image of a twin boundary; (c) HRTEM image of an antiphase boundary.
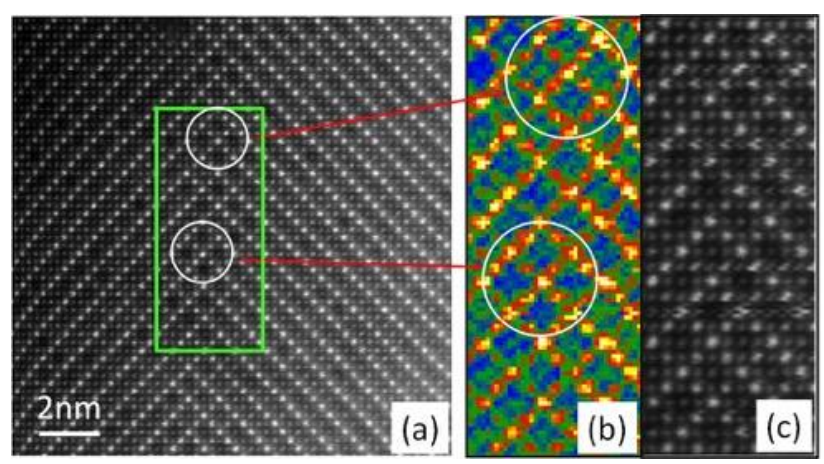

Figure 7. [100] HAADF and EELS data for ceramic $x 90 \mathrm{~A}$ containing a rotational twin boundary: (a) HAADF image, (b) La EELS map, (c) HAADF survey.

Figure 7 illustrates [100] HAADF - EELS data for a $90^{\circ}$ rotational twin boundary in ceramic $\mathrm{x} 90$. HAADF imaging revealed clustering of vacancy rich columns forming a larger unit cell with dimensions of $2 \mathrm{a}_{\text {orthorhombic }} \times 2 \mathrm{a}_{\text {orthorhombic }}=4 \mathrm{a}_{\text {perovskite }}$ at the twin boundary (Figure 7a, circled). From HRTEM images of grains of composition $\mathrm{Sr}_{0.25} \mathrm{La}_{0.5} \mathrm{TiO}_{3}$ in the $\mathrm{SrTiO}_{3}-\mathrm{La}_{2 / 3} \mathrm{TiO}_{3}$ system (equivalent to $\mathrm{x} 80$ in the current notation), Battle et al. ${ }^{30}$ reported a similar phenomenon for the clustering of vacancies with

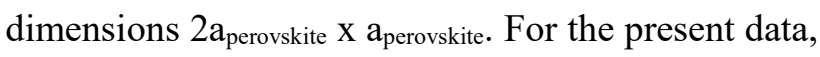
the corresponding La EELS map from the grain boundary, including the region with clustering of vacancies, is shown in Figure $7(b, c)$, verifying the conclusion inferred from the HAADF image (Figure 7a). This localized clustering of vacancies and formation of larger unit-cells will create nonuniformity in the matrix of the material and, as in the arguments highlighted above, will act as additional phonon scattering centers, thus influencing the thermal conductivity of the material.

The final part of electron microscopy investigation was focused on the $\mathrm{SrTiO}_{3}$ rich-compositions, x50 and $\times 30$, that have shown the best thermoelectric properties (highest $\mathrm{ZT}$ values) in the $\mathrm{SrTiO}_{3}-$ $\mathrm{La}_{2 / 3} \mathrm{TiO}_{3}$ system. ${ }^{44,51} \mathrm{HAADF}$ imaging and chemical mapping (Figure 8) again shows the distributions of both vacancies and La cations for $\mathrm{x} 50$ and $\mathrm{x} 30$. Evidence of vacancy clustering was observed for composition $\mathrm{x} 50$. Examples of vacancy clustering are shown within the ellipsoids in Figure 8(a). No evidence for vacancy clustering was observed for $\mathrm{x} 30$. 


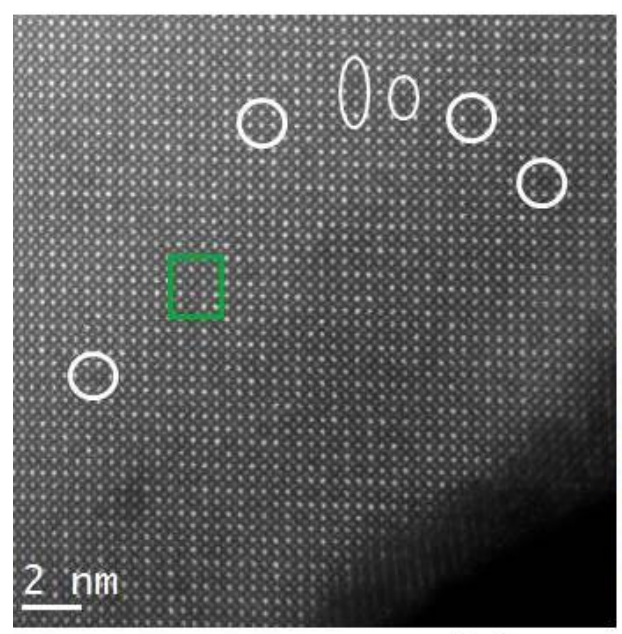

(a)

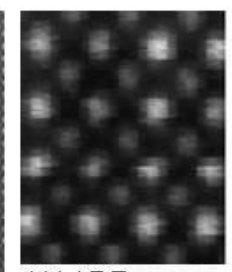

HAADF survey

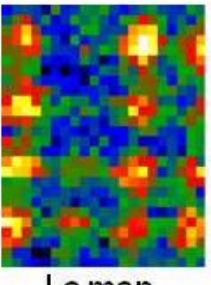

Lamap

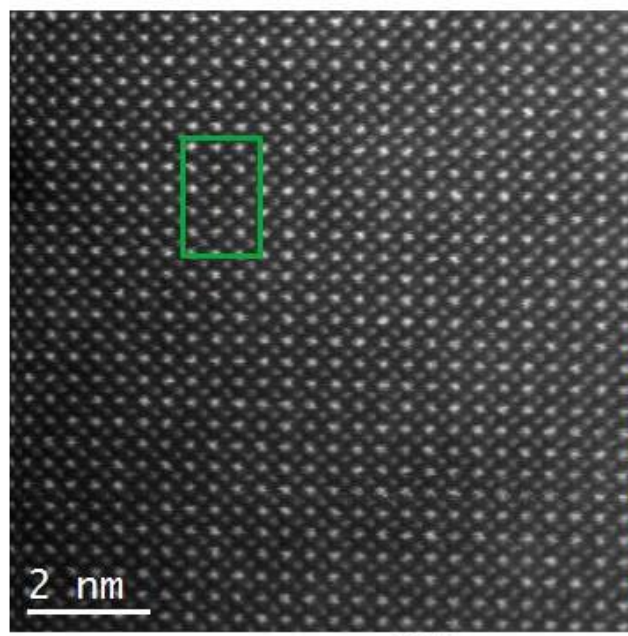

(b)

Figure 8. [100] HAADF - EELS data for ceramics: (a) x50 and (b) x30. Examples of vacancy rich columns are shown inside circles in the HAADF image for $x 50$ (a).

Thermoelectric Properties of Experimentally Synthesized Samples:

\section{A; Samples Sintered in Air Atmosphere.}

The thermal conductivity for all the ceramics as a function of temperature is presented in Figure 9.

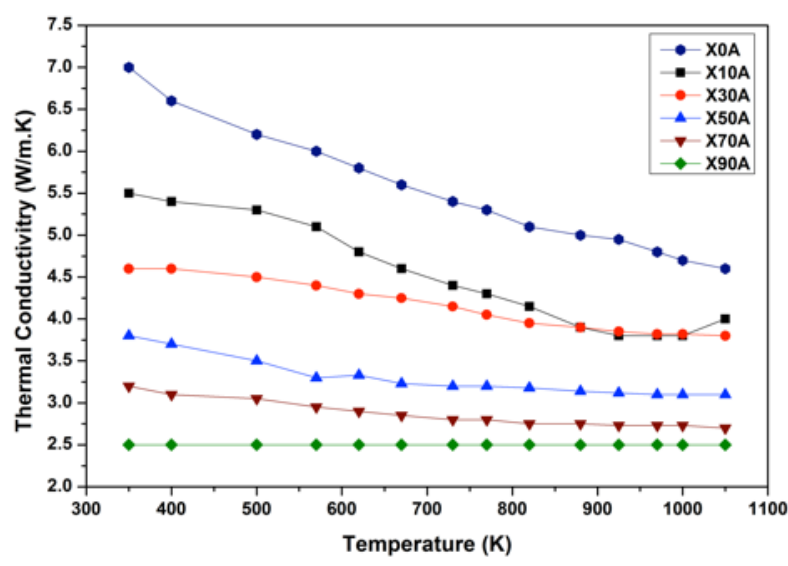

Figure 9. Thermal conductivity of $\mathrm{Sr}_{1-x} \mathrm{La}_{2 \times / 3} \mathrm{TiO}_{3}(x 0 \mathrm{~A}$ to $\mathrm{x} 90 \mathrm{~A})$ as a function of temperature

The measurements demonstrate that altering the composition of this A-site deficient perovskite has the effect of reducing thermal conductivity of $\mathrm{SrTiO}_{3}$ (Figure 9). Above 30 mole $\%$ substitution of $\mathrm{La}_{2 / 3} \mathrm{TiO}_{3}$ into $\mathrm{SrTiO}_{3}$ (i.e. x30 and higher), the materials exhibit near glass-like thermal conductivity, with end member, $\mathrm{x} 90$ showing fully temperature stable behavior with a low thermal conductivity of $2.5 \mathrm{~W} / \mathrm{K} . \mathrm{m}$. At lower levels of substitution this temperature-invariant behavior disappears; however the thermal conductivity is still lower than that of undoped $\mathrm{SrTiO}_{3}$, mainly due to the substitution of Sr by the heavier La ions and the presence of significant numbers of vacancies. The marked decrease of thermal conductivity from sample $\mathrm{x} 30$ to $\mathrm{x} 50$ can be explained by the higher content of orthorhombic phase which in turn introduces more phonon scattering points. There is also evidence of increased vacancy clustering when moving from $\mathrm{x} 30$ to $\mathrm{x} 50$, demonstrated in the electron microscopy results.

This low and glass-like thermal conductivity arises from the following structural characteristics: (i) the presence of heavy La cation and vacancies in the structure; (ii) presence of a layered structure which enhances phonon scattering; (iii) a non-uniform distribution of $\mathrm{La}$ and vacancies in the intermediate layer of the structure leading to non-uniform Ti-O octahedral distortion and Ti-O bond lengths, creating a non-uniform distribution of atomic scale features in the matrix of the material; and (iv) the presence of twin and antiphase boundaries. The first three factors dominate, with the presence of twin and antiphase boundaries playing a relatively minor role because of the large twin boundary spacing (in excess of $20 \mathrm{~nm}) .{ }^{52}$

By cooling the samples slowly after sintering the contribution from $\mathrm{Ti}^{3+}$ was minimized. Across all compositions the estimated contribution from electronic conductivity is less than $0.03 \%$ of total thermal conductivity. The thermal conductivity data reported by Popuri et al. ${ }^{18}$ for $\mathrm{x} 20$ and $\mathrm{x} 40$ are consistent with our data presented in Figure 9. Furthermore, the data of Popuri et al. ${ }^{18}$ shows glasslike thermal conductivity for a sample composition of $\mathrm{x}=0.8$ exhibiting some degree of vacancy disorder. 


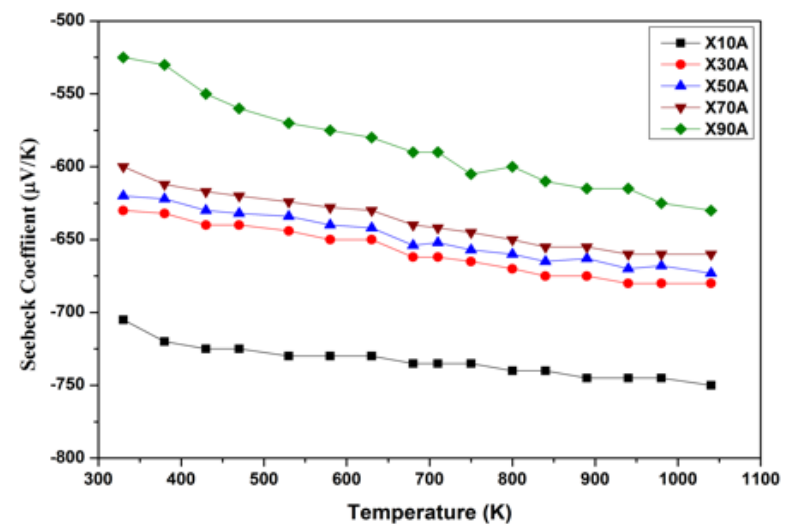

Figure 10. Seebeck coefficients of the air sintered samples.

All the ceramics exhibit a negative Seebeck coefficient indicating n-type conduction (Figure 10). The data show a steady increase in magnitude with temperature; this is typical for $\mathrm{SrTiO}_{3}$ ceramics and reflects the decrease in chemical potential with temperature. ${ }^{53}$ The magnitude of the Seebeck coefficient decreases with increased La content. There is a large decrease from composition $\mathrm{x} 30 \mathrm{~A}$ to $\mathrm{x} 90 \mathrm{~A}$ as the perovskite structure changes from cubic to tetragonal to orthorhombic. However, the A-site deficient perovskite, composition x90A, still shows high Seebeck values in the range of -520 to -650 $\mu \mathrm{V} / \mathrm{K}$. The changes in the Seebeck coefficients are related to the density of states (DOS) about the Fermi level; a high order of symmetry in a crystal will give a steep DOS. The structural phase changes will break the crystal symmetry and therefore lead to reductions in Seebeck coefficients at such transitions.

As expected, all the air sintered ceramics show very low electrical conductivity in the range 0.2 to $0.8 \mathrm{~S} / \mathrm{cm}$ at temperatures of 325 to $1030 \mathrm{~K}$. To evaluate the effect of electrical conductivity, thermal conductivity and Seebeck coefficient on the thermoelectric figure of merit, ceramic samples of the same compositions were prepared in a reducing atmosphere.

\section{B; Thermoelectric Properties of Samples Sintered in Reducing Atmosphere.}

The temperature dependence of the electrical conductivity of the reduced ceramics is shown in Figure 11. The three orders of magnitude increase in the electrical conductivity of the reduced samples compared to that of the air sintered samples is due to a reduction of $\mathrm{Ti}^{4+}$ to $\mathrm{Ti}^{3+}$. The additional electrons in the lattice increase the carrier concentrations and therefore the electrical conductivity. This data shows typical electrical conductivity behavior of semiconducting ceramics. There is an initial increase in the conductivity due to thermal excitation of the electrons followed by a decline in conductivity due to electron phonon scattering. The $\mathrm{X} 30 \mathrm{H}$ samples exhibit the highest electrical conductivity. Additional levels of La doping lead to significant reductions in electrical conductivity.

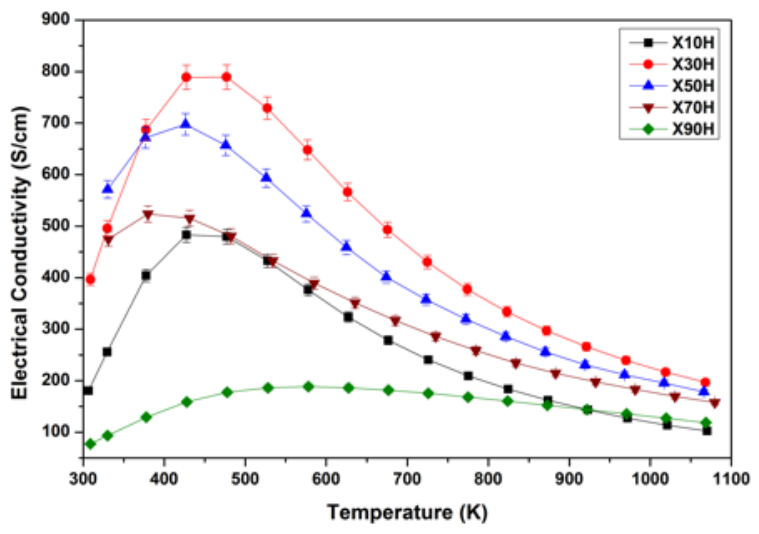

Figure 11. Temperature dependence of Electrical conductivity of the reduced samples.

The thermal conductivity of the reduced ceramics as a function of temperature is presented in Figure 12. The trend is similar to that observed for the air sintered samples, although thermal conductivities of the reduced samples are very slightly higher; this is related to the higher carrier concentrations, which give rise to higher electrical conductivities (Figure 11). Thermal conductivity data for heavily doped compositions (X50 to X90) are almost temperature invariant, with X90 exhibiting the lowest thermal conductivity values (Figure 12) as was the case for the air-sintered samples (Figure 9).

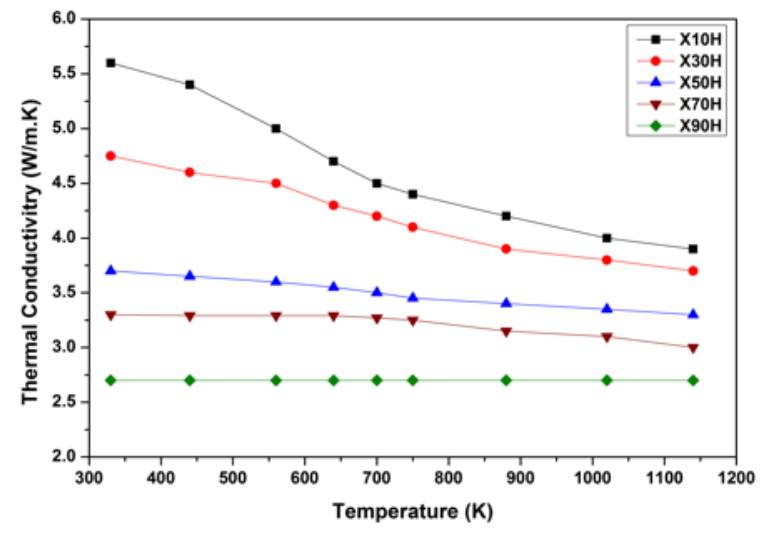

Figure 12. Thermal conductivity for reduced samples.

We believe that the temperature stability of thermal conductivity of the ceramics with increasing $\mathrm{La}_{2 / 3} \mathrm{TiO}_{3}$ content is due to stability of the crystal structure with increasing the temperature, thereby 
maintaining the room temperature structure at the atomic scale; the $\mathrm{Cmmm}$ orthorhombic structure of $\mathrm{La}_{2 / 3} \mathrm{TiO}_{3}$ is stable up to $650 \mathrm{~K}$. Above this temperature up to $900 \mathrm{~K}$, there is a phase transition from $\mathrm{Cmmm}$ orthorhombic to a higher symmetry tetragonal $P 4 / \mathrm{mmm}$. The tetragonal phase has a similar layered structure. Therefore, the presence of similar atomic scale features is believed to help maintain the temperature stability of thermal conductivity. ${ }^{28}$

The Seebeck coefficients for the reduced samples (Figure 13) display the same basic trends as the air sintered samples (Figure 10) but, as expected, the magnitude is substantially reduced for the reduced samples. Again, the reduction in Seebeck coefficient is caused by the increase in carrier concentration, which in turn is caused by the reduction of $\mathrm{Ti}^{4+}$ to $\mathrm{Ti}^{3+}$. The Seebeck coefficients for individual samples increase with increasing La/vacancy content, $\mathrm{X} 90 \mathrm{H}$ being the lowest and $\mathrm{X} 10 \mathrm{H}$ being the highest. The net changes in electrical conductivity and Seebeck coefficient combine to give the temperature dependence in the important thermoelectric parameter, the power factor (Figure 14). For most compositions, there is a peak in the power factor between $500 \mathrm{~K}$ and $600 \mathrm{~K}$ due to the electrical conductivity peak at these temperatures (Figure 12). Whilst sample $\mathrm{X} 10 \mathrm{H}$ exhibits the highest power factor of this series of composition, $0.0016 \mathrm{~W} / \mathrm{m} . \mathrm{K}^{2}$ at $475 \mathrm{~K}$, followed by a rapid decline at higher temperatures, both $\mathrm{X} 30 \mathrm{H}$ and $\mathrm{X} 50 \mathrm{H}$ retain high power factors over a wider range of temperatures.

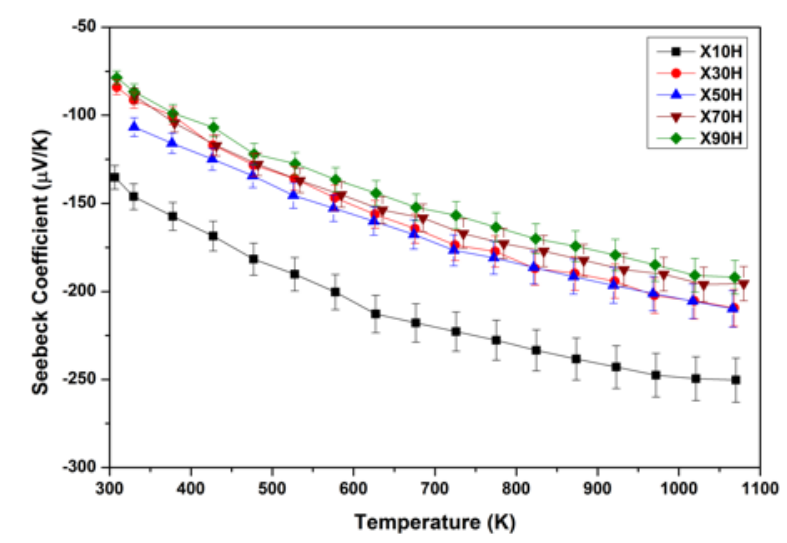

Figure 13. Temperature dependence of Seebeck coefficient for reduced samples.

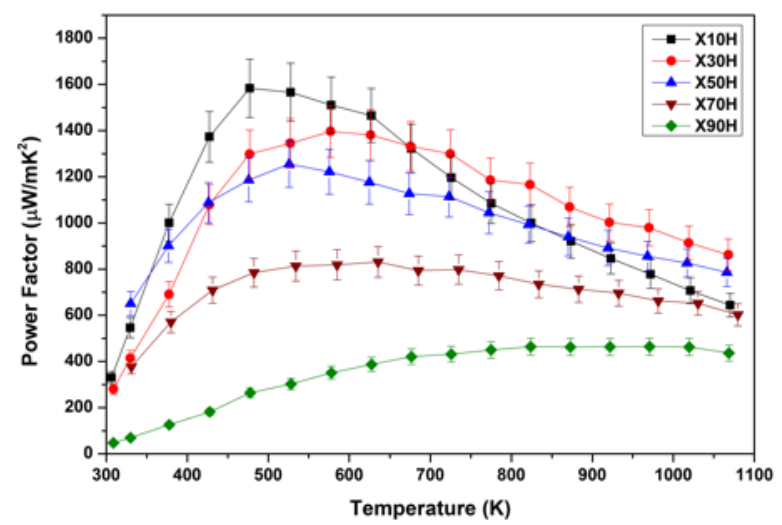

Figure 14. Temperature dependence of the power factor for reduced samples.

Finally, the thermoelectric figure of merit of all reduced ceramics show a steady increase with increasing temperature (Figure 15). The ceramics $\mathrm{X} 10 \mathrm{H}, \mathrm{X} 30 \mathrm{H}$ and $\mathrm{X} 70 \mathrm{H}$ all show a similar trend in $\mathrm{ZT}$ from room temperature to $500 \mathrm{~K}$ where the electrical conductivity peaks (Figure 12). Above 500 $\mathrm{K}$, the ZT increases with temperature for compositions $\mathrm{X} 30 \mathrm{H}, \mathrm{X} 50 \mathrm{H}$ and $\mathrm{X} 70 \mathrm{H}$ but it decreases for the composition with the lowest $\mathrm{La} /$ vacancy content (i.e. X10H). The decrease in thermal conductivity with respect to composition dominates the trend in the overall thermoelectric figure of merit. The maximum dimensionless figure of merit achieved is 0.27 at $870 \mathrm{~K}$ for $\mathrm{X} 50 \mathrm{H}$. The data show that for $\mathrm{SrTiO}_{3}$ improving the figure of merit is achieved mainly by reducing thermal conductivity through introducing $\mathrm{La}$ and $\mathrm{A}$-site vacancies into the lattice.

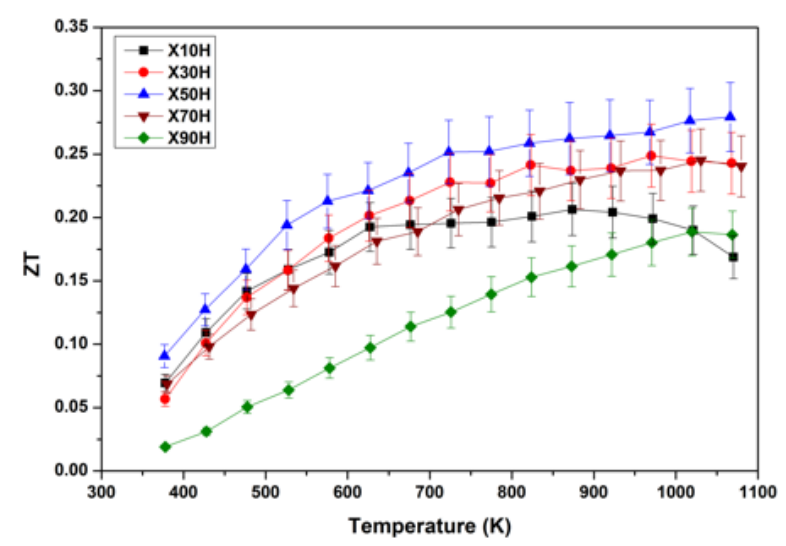

Figure 15. Dimensionless Figure of Merit for reduced samples.

\section{Thermal Properties of Model Structures using Molecular Dynamics.}

Computational techniques are used here to complement the thorough experimental characterization presented above, with the goal of 
determining which factors control the complex behavior of a specific property. Thus, we have calculated the thermal conductivity of model systems at three compositions $\mathrm{x} 20$, x 50 , and $\mathrm{x} 90$. For each composition, we have made up three structures: a random (labelled 'Rand') distribution of $\mathrm{Sr}$, La and A-site vacancies across all A-sites and two layered "LaSr" and "LaV" distributions which are the most sensible arrangements to maximize the separation and the interaction (within the constraint of compositional effects) between $\mathrm{La}$ and $\mathrm{A}$ site vacancies, respectively. This gives us the opportunity to determine unambiguously whether the formation of layers in the perovskite structure or/and the doping is the cause of reduction in thermal conductivity as a function of La and A-site vacancies contents.

The calculated thermal conductivity values from $500 \mathrm{~K}$ to $1100 \mathrm{~K}$ of all model structures are presented in Figure 16. The compositions x20, x50, and $\mathrm{x} 90$ all exhibit a decrease in the thermal conductivity as a function of temperature for all types of structures. This is expected for the thermal conductivity as phonon-phonon scattering with increased temperature leads to a decrease in thermal conductivity.

All x20 models show the largest thermal conductivity whilst all $\mathrm{x} 90$ models have the smallest thermal conductivity across the entire temperature range. The differences between these models, regardless of structure type, depend on the La:Sr:Asite vacancy ratios. As the $\mathrm{La}$ and A-site vacancy concentrations increase, the thermal conductivity decreases. Although Kovalevsky et al. ${ }^{44}$ and $\mathrm{Yu}$ et al. ${ }^{51}$ proposed that oxygen vacancies may have an impact on the thermal conductivity, our calculations cannot directly support this. Our model structures intentionally do not include or take into account the presence of oxygen vacancies and therefore do not provide any further insight into the formation of oxygen vacancies as a mechanism for reduction of the thermal conductivity. The computational models were made to resemble the experimental samples synthesized in air (such as sample $\mathrm{x} 30 \mathrm{~A}$ and $\mathrm{x} 70 \mathrm{~A}$ etc. in Figure 9), and we therefore assumed that there were no oxygen vacancies. In our models the only variable is therefore the $\mathrm{La}(2 \mathrm{x} / 3): \operatorname{Sr}(1-\mathrm{x})$ ratio, and thus, we infer that the reduction in the thermal conductivity intrinsically arises from the introduction of $\mathrm{La}$ and A-site vacancies, and not the stabilization of oxygen vacancies. Although the latter may be a feasible mechanism when the material is synthesized in reducing conditions, the primary focus of this work is to investigate the effect of A-site vacancies alone.
Figure 16 also allows the evaluation of the effect of structural type on thermal conductivity when the composition is constant. At the lowest La content (x20 - Figure 16 a,b,c) the thermal conductivity does not show any differences between the different models, whether the distribution of cations and Asite vacancies is random or layered. This lack of variation is most certainly due to the low concentration of A site vacancies. Given that $80 \%$ of the A-sites are filled with $\mathrm{Sr}$, the three models can arguably be equally considered randomly or layered distributed structures. Therefore, the phonons that can propagate are unchanged by the ordering of the remaining $20 \%$ of species on the A-sites. However, our data for the $\mathrm{x} 20$ composition unambiguously shows that the arrangement of cations on the A sites does not impact on thermal conductivity, indicating that at low concentration of A site vacancies the most important effect on thermal conductivity is the concentration of A site vacancies.

At the mid-range composition of $\mathrm{x} 50$, the thermal conductivity (Figure 16a,b,c) shows some variation, especially for the x50LaSr model $(2.9 \mathrm{~W} / \mathrm{m} . \mathrm{K}$ at $500 \mathrm{~K}$ ), which displays a small increase in the thermal conductivity over the entire temperature range compared to $\mathrm{x} 50 \mathrm{LaV}(2.7 \mathrm{~W} / \mathrm{m} . \mathrm{K}$ at $500 \mathrm{~K})$ and $x 50$ Rand $(2.7 \mathrm{~W} / \mathrm{m} . \mathrm{K}$ at $500 \mathrm{~K})$. Given this small variation in the results, it is not possible to draw any strong conclusions.

At the highest La content, x90 (Figure 16 a,b,c), the thermal conductivities of the different model structures show clear differences. There is a clear increase in the thermal conductivity for $\mathrm{x} 90 \mathrm{LaSr}$ $(2.5 \mathrm{~W} / \mathrm{m} . \mathrm{K}$ at $500 \mathrm{~K})$ across the entire temperature range, whereas $\times 90 \mathrm{LaV}(2.3 \mathrm{~W} / \mathrm{m} . \mathrm{K}$ at $500 \mathrm{~K})$ and $\mathrm{x} 90 \mathrm{R}$ and $(2.1 \mathrm{~W} / \mathrm{m} . \mathrm{K}$ at $500 \mathrm{~K})$ have lower thermal conductivity.

The layered models $x 90 \mathrm{LaSr}$ and $\times 90 \mathrm{LaV}$ are the most sensible arrangements to maximize the separation and the interaction between $\mathrm{La}$ and A site vacancies, respectively. x90 $\mathrm{LaSr}$ ([La $\left.\left.{ }_{0.5}\right]\left[\mathrm{La}_{0.1} \mathrm{Sr}_{0.1} \mathrm{VA}_{0.3}\right] \mathrm{TiO}_{3}\right)$ has fully occupied layers made entirely by La, whereas all other species coexist in the partially occupied layers ( $\mathrm{Sr}, \mathrm{La}$ and $\mathrm{A}$ site vacancies). Rather differently, $\mathrm{x} 90 \mathrm{LaV}$ ([ $\left.\left[\mathrm{La}_{0.4} \mathrm{Sr}_{0.1}\right]\left[\mathrm{La}_{0.2} \mathrm{VA}_{0.3}\right] \mathrm{TiO}_{3}\right)$ has fully occupied layers made by both $\mathrm{La}$ and $\mathrm{Sr}$ whereas $\mathrm{La}$ and $\mathrm{A}$ site vacancies coexist in the partially occupied layers. This indicates that the formation of the layered structure due to the increased doping content (a critical mass of A site vacancies) along with the distribution of the species (i.e. $\mathrm{La}, \mathrm{Sr}$ and $\mathrm{A}$ site vacancies) within the layers are the causes behind the change in thermal conductivity. Our data indicates that although the two layered ( $\mathrm{LaSr}$ and $\mathrm{LaV}$ ) models have the same concentration of A site 
vacancies in the partially occupied layers, a diverse (i.e. $\mathrm{La}$ and $\mathrm{Sr}$ ) occupation of cations in the fully occupied layers (i.e. LaV) will decrease the thermal conductivity. The LaSr will therefore have reduced phonon scattering within the layer compared to $\mathrm{LaV}$, due to less disorder in the fully occupied layer. When this disorder is increased, i.e. x90Rand, then the thermal conductivity decreases even further.

However we also need to consider the stability of these phases. We have therefore calculated the formation energy (Ef) of our $\mathrm{Sr}_{(1-\mathrm{x})} \mathrm{La}_{(2 \times / 3)} \mathrm{TiO}_{3}$ models at $500 \mathrm{~K}$ (Table 4 ) following the reaction:

$$
\begin{aligned}
& (x / 3) \mathrm{La}_{2} \mathrm{O}_{3}+(1-x) \mathrm{SrO}+\mathrm{TiO}_{2} \rightarrow \\
& \mathrm{Sr}_{(1-x)} \mathrm{La}_{(2 x / 3)} \mathrm{TiO}_{3} .
\end{aligned}
$$

Table 4. The formation energies (Ef in $\mathrm{eV})$ of $\mathrm{Sr}_{(1-}$ x) $\mathrm{La}(2 \times / 3) \mathrm{TiO}_{3}$ models at $500 \mathrm{~K}$

\begin{tabular}{|c|c|c|c|}
\hline Ef $(\mathrm{eV})$ & $\mathrm{x} 20$ & $\mathrm{x} 50$ & $\mathrm{x} 90$ \\
\hline Rand & -0.93 & -0.52 & 0.06 \\
\hline LaSr & -0.91 & -0.59 & -0.08 \\
\hline LaV & -0.91 & -0.52 & -0.03 \\
\hline
\end{tabular}

At low concentrations of $\mathrm{La}$, the formation energies are very similar with the $\mathrm{x} 20$ Rand being marginally more stable than the other two models (Table 4). The thermal conductivities of the three phases are also similar (Figure 16).

At $\times 50, x 50 \mathrm{LaSr}$ is more stable than the other two models (Table 4) and has the highest thermal conductivity at this composition (Figure 16).

The same appears to be the case at high $\mathrm{La}$ concentration with $\mathrm{x} 90 \mathrm{LaSr}$ showing greater stability (Table 4) compared to the other models and also highest thermal conductivity (Figure 16). Our results also suggest that although x90Rand has the lowest thermal conductivity, and it is unstable relative to the component oxides. This is in agreement with the experiments that indicate that the $\mathrm{Sr}_{1-\mathrm{x}} \mathrm{La}_{2 \times / 3} \mathrm{TiO}_{3}$ structure for $\mathrm{x} 90$ is a layered structure made of fully occupied layers mostly of $\mathrm{La}$ (if not 100\%), and partially occupied layers more likely to contain $\mathrm{Sr}$. $\mathrm{x} 90 \mathrm{LaV}$ is found to be stable and has a lower thermal conductivity than x90LaSr.

Our computational results can therefore support the experimentation.

Firstly the reduction of thermal conductivity requires a critical mass of A site vacancies. This is illustrated by our $\times 20$ models that show the same thermal conductivity independently of the arrangement of the species on the A sites.
At the intermediate composition (x50), the models show that A site vacancy composition still does not have a major impact on the thermal conductivity. However, as the $\mathrm{x} 50 \mathrm{LaV}$ has a lower thermal conductivity compared to $\mathrm{x} 50 \mathrm{LaSr}$, this suggests that as the concentration of A site vacancies increases the arrangement of other species becomes more important as clustering starts occurring, as shown by the experiments (Figure 7).

At composition $\times 90$, there is a critical mass of A site vacancies and thus the thermal conductivity is significantly lowered compared to $\mathrm{x} 20$ and $\mathrm{x} 50$. In addition, the different models for $\mathrm{x} 90$ show a strong variation in thermal conductivity, due to the effect of the distribution of species on the A sites and the arrangement of A site vacancies. These results suggest that experimental processing engineered to maximize the interaction between $\mathrm{La}$ and $\mathrm{A}$ site vacancies, as in the LaV model, will lead to lowering of the thermal conductivity further.

\section{Comparison with Experimental Data. Since our} primary goal is to investigate the effect of A-site vacancies on the thermal conductivity, we have used the computational data to interpret the experiments (Figure 9). As several structures are used for our computational investigation, the first step is to determine the most suitable structure to compare with the corresponding experimental results. Obviously for the $\times 20$ calculations, any of the computational model structures, which can be considered equivalent, are viable as there are no marked differences in the resulting thermal conductivity; therefore the $\mathrm{x} 20 \mathrm{Rand}$ results are selected as these represent the most similar structure to what is observed experimentally and the structure with the lowest formation energy (Table 4). The experimental samples that can be closely compared with the computational $\mathrm{x} 20$ data are either $\mathrm{x} 10$ or $\mathrm{x} 30$, which fall on either side of this composition. As x10 exhibits different behavior to the rest of the ceramics in the series (i.e. a steeper gradient in the range $500 \mathrm{~K}$ to $1100 \mathrm{~K}$ due to the small number of defects), we use x30 ceramics for comparison. For the experimental $\mathrm{x} 50$, we use $\mathrm{x} 50 \mathrm{LaSr}$ as a comparison, as this structure has the lowest formation energy (Table 4) and contains A-site vacancies / $\mathrm{La}$ clusters as seen experimentally (Figure 8a). Finally, for the ceramic x90, x90 LaSr is selected for comparison as, experimentally, only a layered structure can be synthesized, and it has the lowest formation energy (Table 4). Indeed, the layered structure in the experimental ceramic consists of a fully occupied La layer with the remaining cations partially filling every other layer, which is best represented by the computational 
x90 LaSr structure. So, to summarize we will use $\mathrm{x} 20$ Rand, $\mathrm{x} 50 \mathrm{LaSr}$ and $\mathrm{x} 90 \mathrm{LaSr}$ to compare to experimental data for ceramics x $20, x 50$ and $\mathrm{x} 90$ respectively.

The comparison (Figure 17) between the computational (Figure 16) (filled symbols) and the experimental (hollow symbols) thermal conductivity data of samples synthesized in air (Figure 9) from $500 \mathrm{~K}$ to $1100 \mathrm{~K}$ shows the same qualitative trends. The thermal conductivity for both datasets decreases as the temperature increases due to phonon-phonon scattering becoming the dominant mechanism over phonon-defect scattering.

The magnitude of the experimental data is different from the simulated data. This is expected as we are using very simple computational models that do not contain the complexity of the experimental samples. From a computational point of view, this was necessary if we were to disentangle the effect of doping and the formation of layered perovskite materials. Furthermore we use classical molecular dynamics calculations which use a potential model (a set of parameterized analytical equations) which reproduce the properties of materials although shifted in magnitude. This is common for this kind of calculations, but it is also common for calculations using high level of theory such as ab initio calculations.

The thermal conductivity for both the experimental and computational data decreases with increasing La and A-site vacancy contents due to increased phonon scattering from the vacant sites as well as the larger ion size of the La cations. The decrease in thermal conductivity amongst the computational structures is also in line with the one displayed by the experimental ceramics. This is consistent with the increase in doping concentration and corresponding phonon scattering between $\times 30$ and $\mathrm{x} 50$ but also a component due to the formation of layers in the perovskite structure between $\mathrm{x} 50$ and $\mathrm{x} 90$. Since thermal conductivity is one of the main factors controlling thermoelectric performance we now have significant insight into routes to designing and synthesizing improved perovskite-structured thermoelectrics.
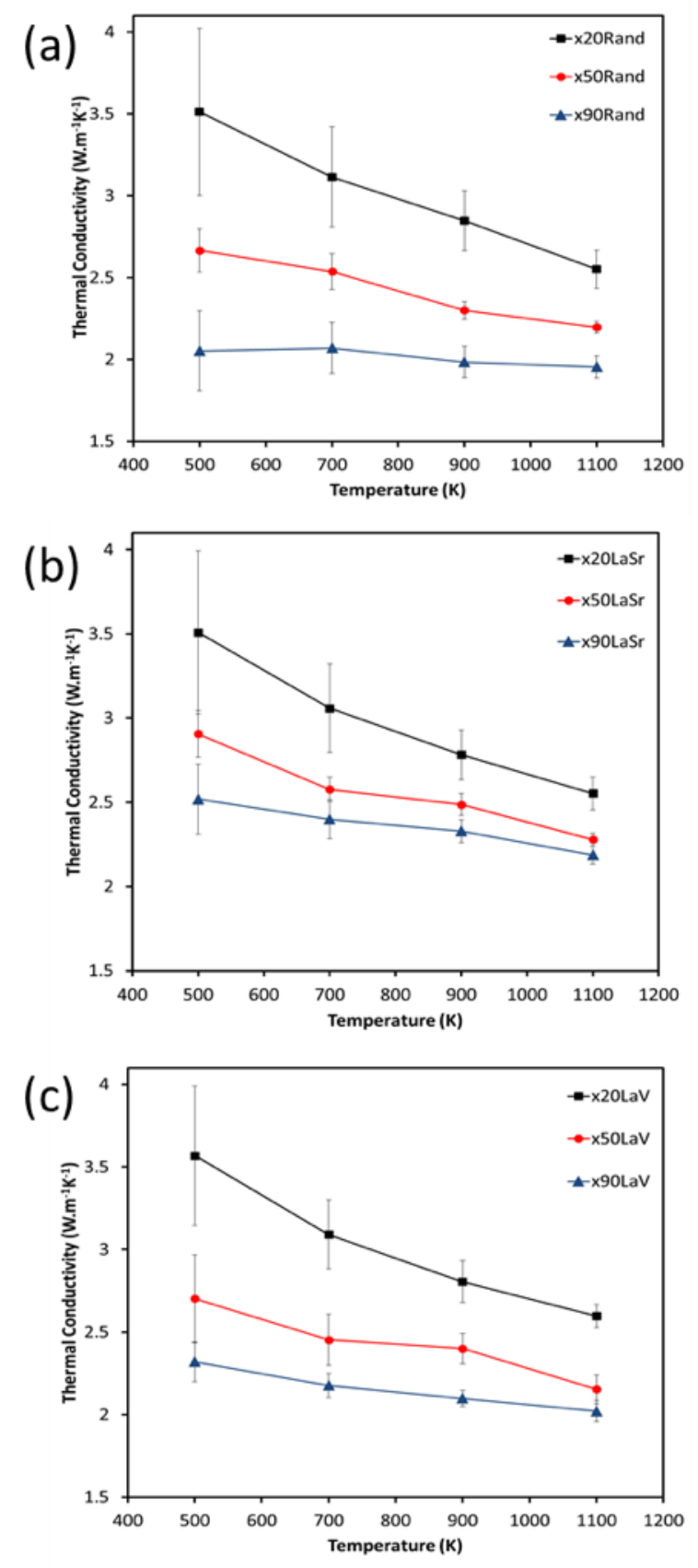

Figure 16 The thermal conductivity values of the $x 20, x 50$ and $x 90$ models in the temperature range of $500-1100 \mathrm{~K}$. (a) A random (labelled 'Rand') distribution of $\mathrm{Sr}$, La and vacancies across all A-sites. (b) A layered system whereby one layer is fully occupied by lanthanum and the other layer is filled with the remaining lanthanum, strontium, and vacancies (labelled 'LaSr'). (c) A layered system whereby one layer is fully occupied by lanthanum and strontium and the other layer is filled with the remaining lanthanum, and vacancies (labelled 'LaV'). 


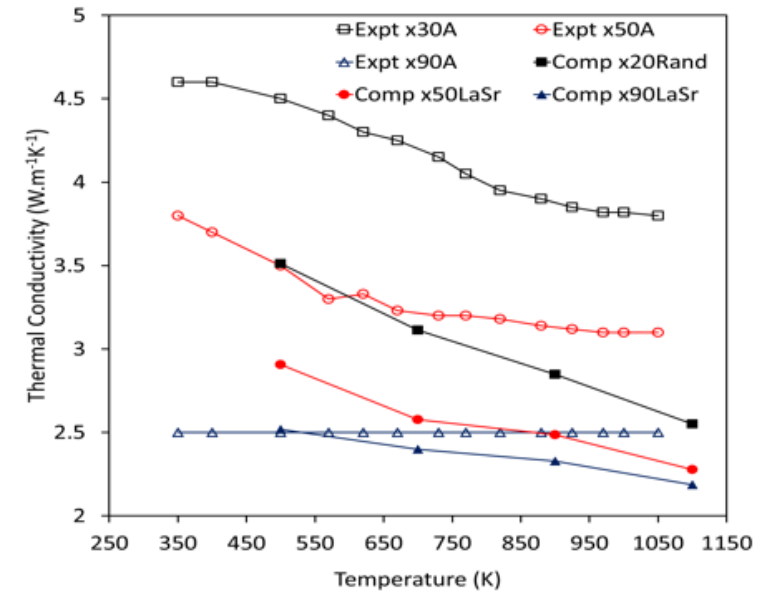

Figure 17. The thermal conductivities of the computational results (filled symbols) with the corresponding experimental results (hollow symbols). The computational results were chosen to best match the crystal structure of the experimental ceramics.

Finally, it is noted that in order to separate the contributions of oxygen vacancies from A-site vacancies we specifically investigated the thermal conductivity of oxygen stoichiometric samples (produced by sintering in air and slow cooling) and oxygen-deficient samples (produced under reducing conditions). The thermal conductivity behaviour of both sets of samples is similar (Figures 9 and 12). Detailed analysis of the role and effect of oxygen vacancies is outside the scope of this work but it is accepted that oxygen vacancies, which may readily exist in perovskite thermoelectrics (in the range of 5 to $10 \%)^{54,55}$ can impact on thermal properties through (i) oxygen vacancies acting as point defects in the structure, leading to different defect reactions, (ii) the development of localized distorted $\mathrm{Ti}$ - O octahedra acting as different phonon scattering centres in the material, and (iii) possible clustering of cation - oxygen vacancies, similar to the clustering of cation vacancies as shown here in Figures 7 and $8 \mathrm{a}$. In order to enhance thermoelectric properties, the definition of routes to control oxygen vacancy concentrations and locations will also be beneficial.

\section{CONCLUSIONS}

We have employed experimental and computational techniques, including atomicresolution STEM-HAADF and STEM-EELS, and molecular dynamics modelling to disentangle the role of La doping in inducing A-site vacancies and of the formation of layers when increasing $\mathrm{La}$ content, in $\mathrm{Sr}_{1-\mathrm{x}} \mathrm{La}_{2 \times 3} \mathrm{TiO}_{3}$ ceramics $(0.0 \leq \mathrm{x} \leq 0.9)$.

At low La content $(\mathrm{x}<0.3)$ the ceramics have a cubic structure (space group $P m \overline{3} m$ ) and A-site vacancies randomly distributed. At intermediate La content, there is a move to vacancy clustering ( $\mathrm{x} \sim$ $0.5)$ and the ceramics are characterized by a mixture of crystal structures (cubic, tetragonal and orthorhombic). Finally, for high La content $(x=0.9)$ there is a transition to orthorhombic symmetry, with doubling of axes along all three lattice directions (with $a-b^{0} c^{0}$ tilt system and space group Cmmm), ordering of vacancies and $\mathrm{La}$, and segregation of vacancies at $90^{\circ}$ twin boundaries leading to the formation of localized supercells.

The thermal conductivity for both the experimental and computational data decreases with increasing $\mathrm{La}$ and $\mathrm{A}$-site vacancy contents due to increased phonon scattering from the vacant sites as well as the larger ion size of La. The clear jump between $\times 30$ and $\times 50$ could be related to the structural transition from cubic + tetragonal (x30) to orthorhombic (x50). High La doped $(\mathrm{x}=0.9)$ samples exhibit the lowest thermal conductivity. The reduction is enhanced by localized clustering of vacancies and the formation of larger unit-cells, thereby creating further non-uniformity in the matrix of the material that act as additional phonon scattering centers.

We infer that the reduction in the thermal conductivity intrinsically arises from the introduction of $\mathrm{La}$ and A-site vacancies, and the formation of the layered structures and not the stabilization of oxygen vacancies (all our samples are synthesized in air). Our modelling supports that the thermal conductivity at high La content is lowered by the formation of a layered structure and due to a critical mass of A site vacancies. However, thermal conductivity can be further lowered when $\mathrm{La}$ and $\mathrm{A}$ site vacancies are distributed so that they maximize their interaction. Hence, we suggest that synthetic work is needed to further advance the nanostructuring of La doped $\mathrm{SrTiO}_{3}$.

\section{AUTHOR INFORMATION}

Corresponding Authors

${ }^{*}$ Email: Robert.Freer@manchester.ac.uk

*Email: S.C.Parker@bath.ac.uk

\section{ACKNOWLEDGEMENTS}

The authors gratefully acknowledge the support and the provision of funding from EPSRC for this work (EP/H043462, EP/I036230/1, EP/L014068/1, $\mathrm{EP} / \mathrm{L} 017695 / 1, \mathrm{EP} / \mathrm{I} 03601 \mathrm{X} / 1$ and EP/K016288/1). This work made use of ARCHER, the UK's national HPC, via the Materials Chemistry Consortium funded by the EPSRC (EP/L000202) in addition to the HPC Balena at the University of Bath, the HPC Hydra at the University of Loughborough and the 
HPC Orion at the University of Huddersfield. SuperSTEM is the EPSRC National Facility for Advanced Electron Microscopy, supported by EPSRC. All research data supporting this study are openly available within this publication.

\section{REFERENCES}

(1) Snyder, G. J.; Toberer, E. S. Complex Thermoelectric Materials. Nat. Mater. 2008, 7, 105-114.

(2) Koumoto, K.; Wang, Y. F.; Zhang, R. Z.; Kosuga, A.; Funahashi, R. Oxide Thermoelectric Materials: A Nanostructuring Approach. Annu. Rev. Mater. Res. 2010, 40, 363-394.

(3) Fergus, J. W. Oxide Materials for High Temperature Thermoelectric Energy Conversion. J. Eur. Ceram. Soc. 2012 32, 525-540.

(4) Norman, C.; Azough, F.; Freer, R. In Thermoelectric Materials and Devices; The Royal Society of Chemistry: 2017; 60-82.

(5) Funahashi, S.; Nakamura, T.; Kageyama, K.; leki, H. Monolithic Oxide-Metal Composite Thermoelectric Generators for Energy Harvesting. J. Appl. Phys. 2011, 109, 124509.

(6) Terasaki, I.; Sasago, Y.; Uchinokura, K. Large Thermoelectric Power in $\mathrm{NaCO}_{2} \mathrm{O}_{4}$ Single Crystals. Phys. Rev. B 1997, 56, 12685-12687.

(7) Baran, J. D.; Molinari, M.; Kulwongwit, N.; Azough, F.; Freer, R.; Kepaptsoglou, D.; Ramasse, Q. M.; Parker, S. C. Tuning Thermoelectric Properties of Misfit Layered Cobaltites by Chemically Induced Strain. J. Phys. Chem. C 2015, 119, 21818-21827.

(8) Baran, J. D.; Kepaptsoglou, D.; Molinari, M.; Kulwongwit, N.; Azough, F.; Freer, R.; Ramasse, Q. M.; Parker, S. C. Role of Structure and Defect Chemistry in HighPerformance Thermoelectric Bismuth Strontium Cobalt Oxides. Chem. Mater. 2016, 28, 7470-7478.

(9) Combe, E.; Funahashi, R.; Barbier, T.; Azough, F.; Freer, R. Decreased Thermal Conductivity in $\mathrm{Bi}_{2} \mathrm{Sr}_{2} \mathrm{Co}_{2} \mathrm{O}_{x}$ Bulk Materials Prepared by Partial Melting. J. Mater. Res. 2016, 31, 1296-1305.

(10) Bocher, L.; Aguirre, M. H.; Robert, R.; Logvinovich, D.; Bakardjieva, S.; Hejtmanek, J.; Weidenkaff, A. HighTemperature Stability, Structure and Thermoelectric Properties of $\mathrm{CaMn}_{1-\mathrm{x}} \mathrm{Nb}_{\mathrm{x}} \mathrm{O}^{3}$ Phases. Acta Mater. 2009, 57, 5667-5680.

(11) Molinari, M.; Tompsett, D. A.; Parker, S. C.; Azough, F.; Freer, R. Structural, Electronic and Thermoelectric Behaviour of $\mathrm{CaMnO}_{3}$ and $\mathrm{CaMnO}_{3-\delta}$. J. Mater. Chem. A 2014, 2, 14109-14117.

(12) Srivastava, D.; Azough, F.; Freer, R.; Combe, E.; Funahashi, R.; Kepaptsoglou, D. M.; Ramasse, Q. M.; Molinari, M.; Yeandel, S. R.; Baran, J. D.; Parker, S. C. Crystal Structure and Thermoelectric Properties of Sr-Mo Substituted $\mathrm{CaMnO}_{3}$ : A Combined Experimental and Computational Study. J. Mater. Chem. C 2015, 3, 1224512259.

(13) Ohta, H.; Sugiura, K.; Koumoto, K. Recent Progress in Oxide Thermoelectric Materials: P-Type $\mathrm{Ca}_{3} \mathrm{Co}_{4} \mathrm{O}_{9}$ and $\mathrm{N}$ Type $\mathrm{SrTiO}_{3}$. Inorg. Chem. 2008, 47, 8429-8436.

(14) Muta, H.; Kurosaki, K.; Yamanaka, S. Thermoelectric Properties of Reduced and La-Doped SingleCrystalline $\mathrm{SrTiO}_{3}$. J Alloy Compd 2005, 392, 306-309.

(15) Okuda, T.; Nakanishi, K.; Miyasaka, S.; Tokura, Y. Large Thermoelectric Response of Metallic Perovskites: $\mathrm{Sr}_{1}$. ${ }_{x} \mathrm{La}_{x} \mathrm{TiO}_{3}(0<\sim \mathrm{x}<\sim 0.1)$. Phys. Rev. B 2001, 63, 113104.

(16) Ohta, S.; Nomura, T.; Ohta, H.; Koumoto, K. HighTemperature Carrier Transport and Thermoelectric Properties of Heavily La-or Nb-Doped $\mathrm{SrTiO}_{3}$ Single Crystals. J. Appl. Phys. 2005, 97, 034106.
(17) Jackson, S. S.; Azough, F.; Freer, R. NeodymiumStrontium Titanate: A New Ceramic for an Old Problem. J. Electron. Mater. 2014, 43, 2331-2336.

(18) Popuri, S. R.; Scott, A. J. M.; Downie, R. A.; Hall, M. A.; Suard, E.; Decourt, R.; Pollet, M.; Bos, J. W. G. Glass-Like Thermal Conductivity in $\mathrm{SrTiO}_{3}$ Thermoelectrics Induced by aSite Vacancies. RSC Adv. 2014, 4, 33720-33723.

(19) Mehdizadeh Dehkordi, A.; Bhattacharya, S.; Darroudi, T.; Graff, J. W.; Schwingenschlögl, U.; Alshareef, $H$. N.; Tritt, T. M. Large Thermoelectric Power Factor in PrDoped $\mathrm{SrTiO}_{3-\delta}$ Ceramics Via Grain-Boundary-Induced Mobility Enhancement. Chem. Mater. 2014, 26, 2478-2485.

(20) Yeandel, S. R.; Molinari, M.; Parker, S. C. Nanostructuring Perovskite Oxides: The Impact of $\mathrm{SrTiO}_{3}$ Nanocube 3D Self-Assembly on Thermal Conductivity. RSC Adv. 2016, 6, 114069-114077.

(21) Azough, F.; Cernik, R. J.; Schaffer, B.; Kepaptsoglou, D.; Ramasse, Q. M.; Bigatti, M.; Ali, A.; MacLaren, I.; Barthel, J.; Molinari, M.; Baran, J. D.; Parker, S. C.; Freer, R. Tungsten Bronze Barium Neodymium Titanate $\left(\mathrm{Ba}_{6-3 n} \mathrm{Nd}_{8+2 n} \mathrm{Ti}_{18} \mathrm{O}_{54}\right)$ : An Intrinsic Nanostructured Material and Its Defect Distribution. Inorg. Chem. 2016, 55, 3338-3350.

(22) Azough, F.; Freer, R.; Yeandel, S. R.; Baran, J. D.; Molinari, M.; Parker, S. C.; Guilmeau, E.; Kepaptsoglou, D.; Ramasse, Q.; Knox, A.; Gregory, D.; Paul, D.; Paul, M.; Montecucco, A.; Siviter, J.; Mullen, P.; Li, W.; Han, G.; Man, E. A.; Baig, H.; Mallick, T.; Sellami, N.; Min, G.; Sweet, T. $\mathrm{Ba}_{6-3 x} \mathrm{Nd}_{8+2 x} \mathrm{Ti}_{18} \mathrm{O}_{54}$ Tungsten Bronze: A New HighTemperature N-Type Oxide Thermoelectric. J. Electron. Mater. 2016, 45, 1894-1899.

(23) Srivastava, D.; Azough, F.; Molinari, M.; Parker, S. C.; Freer, R. High-Temperature Thermoelectric Properties of $(1-x) \mathrm{SrTiO}_{3}-(\mathrm{x}) \mathrm{La}_{1 / 3} \mathrm{NbO}_{3}$ Ceramic Solid Solution. J. Electron. Mater. 2015, 44, 1803-1808.

(24) Evarestov, R. A.; Blokhin, E.; Gryaznov, D.; Kotomin, E. A.; Maier, J. Phonon Calculations in Cubic and Tetragonal Phases of SrTiO3: A Comparative LCAO and Plane-Wave Study. Phys. Rev. B 2011, 83, 134108.

(25) Azough, F.; Wang, W.; Freer, R. The Crystal Structure of $\mathrm{LaAlO}_{3}$-Stabilized $\mathrm{La}_{2 / 3} \mathrm{TiO}_{3}$ Ceramics: An HRTEM Investigation. J. Am. Ceram. Soc. 2009, 92, 20932098.

(26) Zhang, Z.; Lumpkin, G. R.; Howard, C. J.; Knight, K. S.; Whittle, K. R.; Osaka, K. Structures and Phase Diagram for the System $\mathrm{CaTiO}_{3}-\mathrm{La}_{2 / 3} \mathrm{TiO}_{3}$. J. Solid State Chem. 2007, 180, 1083-1092.

(27) Howard, C. J.; Lumpkin, G. R.; Smith, R. I.; Zhang, Z. Crystal Structures and Phase Transition in the System $\mathrm{SrTiO}_{3}-\mathrm{La}_{2 / 3} \mathrm{TiO}_{3}$. J. Solid State Chem. 2004, 177, 27262732.

(28) Howard, C. J.; Zhang, Z. Structures and Phase Transition in the Layered Perovskite $\mathrm{La}_{0.6} \mathrm{Sr}_{0.1} \mathrm{TiO}_{3}$ : A New Orthorhombic Structure Solved from High-Resolution Diffraction in Combination with Group Theoretical Analysis. J. Phys. Condens. Matter 2003, 15, 4543-4553.

(29) Howard, C. J.; Zhang, Z.; Carpenter, M. A.; Knight, K. S. Suppression of Strain Coupling in Perovskite $\mathrm{La}_{0.6} \mathrm{Sr}_{0.1} \mathrm{TiO}_{3}$ by Cation Disorder. Phys. Rev. B 2007, 76, 054108.

(30) Battle, P. D.; Bennett, J. E.; Sloan, J.; Tilley, R. J. D.; Vente, J. F. A-Site Cation-Vacancy Ordering in $\mathrm{Sr}_{1-3 \times 2} \mathrm{La}_{\mathrm{x}} \mathrm{TiO}_{3}$ : A Study by HRTEM. J. Solid State Chem. 2000, 149, 360-369.

(31) Azough, F.; Freer, R.; Schaffer, B. Direct Observation of a-Site Vacancies and a Twin Boundary Structure in $\mathrm{La}_{2 / 3} \mathrm{TiO}_{3}$-Based Ceramics Using HAADF/STEM. J. Am. Ceram. Soc. 2010, 93, 1237-1240.

(32) Topas 4.2 Software, Bruker AXS: Karlsruhe, Germany.

(33) Green, M. S. Markoff Random Processes and the Statistical Mechanics of Time-Dependent Phenomena. li. Irreversible Processes in Fluids. J. Chem. Phys. 1954, 22, 398-413. 
(34) Kubo, R. Statistical-Mechanical Theory of Irreversible Processes. I. General Theory and Simple Applications to Magnetic and Conduction Problems. J. Phys. Soc. Jpn. 1957, 12, 570-586.

(35) Plimpton, S. Fast Parallel Algorithms for ShortRange Molecular Dynamics. J Comput. Phys. 1995, 117, 119.

(36) Canepa, P. New Insights on Iron and Lead-Based Materials Beyond Density Functional Theory. PhD Thesis, University of Kent, Canterbury, 2012.

(37) McGaughey, A. J. H.; Kaviany, M. J., Molecular Dynamics Calculations of the Thermal Conductivity of Silica Based Crystals. In 8th AIAA/ASME Joint Thermophysics and Heat Transfer Conference, AIAA-2002-3343, St. Louis, Missouri, 2002.

(38) Bashir, J.; Khan, R. T.; Butt, N. M.; Heger, G. Thermal Atomic Displacement Parameters of SrO. Powder Diffraction. 2002, 17, 222-224.

(39) Baur, W. H.; Khan, A. A. Rutile-type Compounds. IV. $\mathrm{SiO}_{2}, \mathrm{GeO}_{2}$ and a Comparison with Other Rutile-type Structures. Acta Crystallogr. Sect. B 1971, 27, 2133-2139.

(40) Aldebert, P.; Traverse, J. P. Etude par diffraction Neutronique des Structures de Haute Temperature de $\mathrm{La}_{2} \mathrm{O}_{3}$ et $\mathrm{Nd}_{2} \mathrm{O}_{3}$. Mater. Res. Bull. 1979, 14, 303-323.

(41) Watson, G. W.; Kelsey, E. T.; deLeeuw, N. H.; Harris, D. J.; Parker, S. C. Atomistic Simulation of Dislocations, Surfaces and Interfaces in Mgo. J. Chem. Soc., Faraday Trans. 1996, 92, 433-438.

(42) Ali, R.; Izumi, F.; Yashima, M. Neutron Powder Diffraction Study of a Phase Transition in $\mathrm{La}_{0.68}\left(\mathrm{Ti}_{0.95} \mathrm{Al}_{0.05}\right) \mathrm{O}_{3}$. J. Am. Ceram. Soc. 2006, 89, 3805-3811.

(43) Lu, Z.; Zhang, H.R.; Lei,W.; Sinclair, D.C.; Reaney, I.M. High-Figure-of-Merit Thermoelectric La-Doped A-SiteDeficient $\mathrm{SrTiO}_{3}$ Ceramics, Chem. Mater. 2016, 28, 925-935.

(44) Kovalevsky, A. V.; Yaremchenko, A. A.; Populoh, S.; Weidenkaff, A.; Frade, J. R. Effect of A-Site Cation Deficiency on the Thermoelectric Performance of Donor-Substituted Strontium Titanate. J. Phys. Chem. C 2014, 118, 4596-4606.

(45) Howard, C. J.; Kennedy, B. J.; Woodward, P. M. Ordered Double Perovskites - a Group-Theoretical Analysis. Acta Crystallogr. Sect. B 2003, 59, 463-471.

(46) Jones, G. O.; Thomas, P. A. Investigation of the Structure and Phase Transitions in the Novel a-Site Substituted Distorted Perovskite Compound $\mathrm{Na}_{0.5} \mathrm{Bi}_{0.5} \mathrm{TiO}_{3}$. Acta Crystallogr. Sect. B 2002, 58, 168-178.

(47) Danaie, M.; Kepaptsoglou, D.; Ramasse, Q. M.; Ophus, C.; Whittle, K. R.; Lawson, S. M.; Pedrazzini, S.; Young, N. P.; Bagot, P. A. J.; Edmondson, P. D. Characterization of Ordering in a-Site Deficient Perovskite $\mathrm{Ca}_{1-\mathrm{x}} \mathrm{La}_{2 \times / 3} \mathrm{TiO}_{3}$ Using STEM/EELS. Inorg. Chem. 2016, 55, 9937-9948.

(48) Wang, Y.; Liebermann, R. C. Electron Microscopy Study of Domain Structure Due to Phase Transitions in Natural Perovskite. Phys. Chem. Miner. 1993, 20, 147-158.

(49) Lowndes, R. Structural and Microwave Dielectric Properties of Ceramics of $\mathrm{Ca}_{(1-x)} \mathrm{Nd}_{2 \times / 3} \mathrm{TiO}_{\text {s. }}$. PhD Thesis, The University of Manchester, Manchester, 2012.

(50) Wondratschek, H.; Jeitschko, W. Twin Domains and Antiphase Domains. Acta Crystallogr. Sect. A 1976, 32, 664 666.

(51) Yu, C.; Scullin, M. L.; Huijben, M.; Ramesh, R.; Majumdar, A. Thermal Conductivity Reduction in OxygenDeficient Strontium Titanates. Appl Phys Lett 2008, 92, 191911-191911.

(52) Mao, J; Wang, Y.; Liu, Z.; Ge, B.; Ren, Z.; Phonon Scattering by Nanoscale Twin Boundaries, Nano Energy, 2017, 32, 174-179

(53) Ohta, S.; Nomura,T.; Ohta, H.; Koumoto, K. Hightemperature Carrier Transport and Thermoelectric Properties of Heavily La- or Nb-doped $\mathrm{SrTiO}_{3}$ single crystal, J Appl Phys 2005, 97, 034106.

(54) Chen, C.; Zhang, T.; Donelson, R.; Tan, T.T.; Li, S. Effects of Yttrium Substitution and Oxygen Deficiency on the Crystal Phase, Microstructure, and Thermoelectric Properties of $\mathrm{Sr}_{1-1.5 \mathrm{x}} \mathrm{Y}_{\mathrm{x}} \mathrm{TiO}_{3-\delta}(0 \leq \mathrm{x} \leq 0.15)$. J. Alloys Compd., 2015, 629, $49-54$.

(55) Srivastava, D.; Norman, C.; Azough, F.; Schäfer, M.C.; Guilmeau, E.; Kepaptsoglou, D.; Ramasse, Q.M.; Nicotra,G.; Freer, R. Tuning the Thermoelectric Properties of A-site Deficient $\mathrm{SrTiO}_{3}$ Ceramics by Vacancies and Carrier Concentration, Phys. Chem. Chem. Phys. 2016, 18, 2647526486 
Table of Contents Graphic
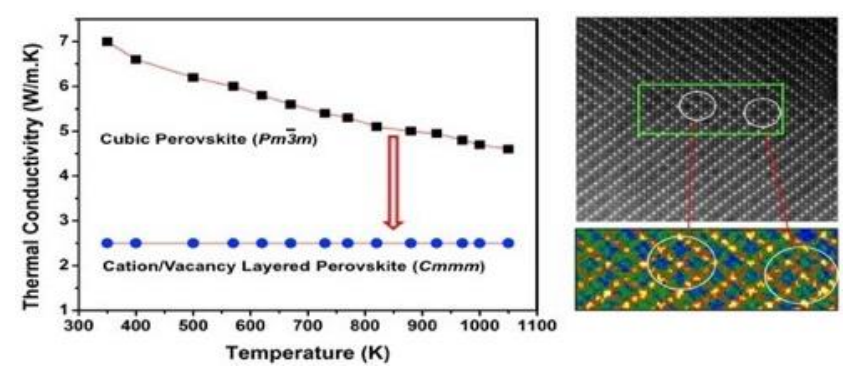